\title{
1. The Lightest Beam Method - a methodology to find ultimate steel savings and reduce embodied carbon in steel framed buildings
}

\author{
Michał P. Drewniok ${ }^{\mathrm{a}, *}$, Jamie Campbell ${ }^{\mathrm{a}}$, John Orr ${ }^{\mathrm{a}}$ \\ ${ }^{a}$ University of Cambridge, Cambridge, UK
}

5 Abstract

Building carbon intensity is related to material choice, but more importantly, material volume. The building structural frame itself is responsible for $20-30 \%$ of whole-life carbon over 50 years. This figure will double once we build net-zero operational carbon buildings. Carbon savings in the use of materials are therefore the key to reducing the environmental impact of buildings. Recent studies have shown that up to $40 \%$ of material in building structural frames could be successfully removed without affecting design code compliance. This unnecessary overdesign of buildings is in part due to a lack of structural optimisation, and acceptance by designers of conservative serviceability assumptions that represent the "low hanging fruit" of reducing embodied carbon in buildings. This paper examines steel frames buildings to determine the carbon savings that can be achieved for cross-section optimisation, as this is the most accessible form of optimisation, without changing the floor system and beam layout. For this purpose the Lightest Beam Method (LBM) was developed that studied non-composite universal beams (UB) members in buildings. Choosing the lightest section with the Eurocodes we can achieve $26.5 \%$ of steel savings by mass, with a half of beams governed by serviceability limit states (SLS). If deflection is calculated using variable loads, the proportion of beams governed by the SLS drops to $31.1 \%$ giving additional $2.2 \%$ mass savings. The highest steel savings of $34.5 \%$ can be achieved for lower natural frequency assumptions $(3 \mathrm{~Hz})$ and using the average rather than the characteristic steel yield strength. In this case the proportion of beams by mass governed by SLS drops to $19.7 \%$. Based on available case studies it was found that $1 / 3$ of steel in the frames could have been saved which represents $36 \%$ of initial embodied carbon or $5 \%$ of whole-life carbon for the building over 60 years.

\section{1. Introduction}

The construction of buildings and infrastructure make up a significant proportion of the global economy at around 13\% of the global GDP [1]. Buildings and construction are responsible for almost 39\% of energy-related carbon dioxide emissions and 36\% of global energy use [2]. A quarter of these emissions in $2017\left(3.8 \mathrm{GtCO}_{2}\right)$ were connected to production, transport and use of construction materials for buildings. Cement and steel alone 
represented $6 \%$ of global $\mathrm{CO}_{2}\left(2 \mathrm{GtCO}_{2}\right)$ [3]. With a global population increase to $10.8 \mathrm{bn}$ in 2050 [4], the UN predicts that global floor area will almost double to $415 \mathrm{bn} \mathrm{m}^{2}$ by 2050 [3]. One quarter of this new build will be located in China, India and Africa $\left(107 \mathrm{bn} \mathrm{m}^{2}\right)$ [2]. In addition to the population growth, it is expected that in 2050 more than $68 \%$ of the population will live in cities, compared to a half in 2010 [4]. Around $70 \%$ of buildings by floor area are going to be constructed in countries that currently do not have any mandatory building energy codes [3]. To meet the $\mathrm{CO}_{2}$ emission targets set by the $21^{\text {st }}$ Conference of the Parties [5], enhancements in the material production and use across different industries are necessary $[6,7]$. With increasing demand for new buildings and infrastructure, significant emission reduction strategies should be immediately implemented. If we do not reduce future emissions, we will consume our remaining 2050 carbon budget within 12 years [8].

The environmental impact of buildings, and thus the carbon intensity, depends on the materials and processes related to the production of the building $[9,10]$. Much of current research is focused on operational energy, which is seeing a move towards net-zero in terms of whole-life energy. Consequently, it is estimated that embodied energy from materials will represent almost $100 \%$ of total building emissions by 2050 [11, 12]. A part of embodied carbon, initial embodied carbon, is material dependent and is relatively easy to assess. Unfortunately there is a lack of comparable methodologies, data, and regulation that lead to a reduction of the embodied impacts $[13,14,15,16]$, especially embodied carbon in use (e.g. due to maintenance, repair, replacement, refurbishment) $[17,18,19]$. Currently, for an average office building located in London and an assumed 60-year service life, $1 / 3$ of whole-life building emissions represent initial embodied carbon (2/3 of which comes from the building structure), 1/3 embodied carbon in-use and emissions connected to end-of building life, and 1/3 operational carbon $[9,17]$. For a 50-year lifespan commercial building (design life-time according to the EC [20]) the structural frames represent 20-30\% of whole-life carbon (WLC) [21, 22, 23], 25\% of which come from the columns [24]. The reduction of embodied carbon have a significant impact on achieving "Net zero whole-life carbon" building [17].

The vast majority of structural elements in the UK are designed according to the Eurocodes [20] using Limit State Design (LSD) methods. Limit state design is a philosophy under which structures are designed such that the probability that a number of performance criteria are exceeded is deemed to be acceptably small during the required functional lifetime of the structure. When a structure, or element within a structure, ceases to satisfy one or more of these performance criteria, it is deemed to have exceeded a limit state and thus does not meet the design requirements. The ultimate limit states (ULS) are those which concern "the safety of people and/or the safety of the structure" [25] whereas the serviceability limit states (SLS) concern "the functioning of the structure 
41 or structural members under normal use; the comfort of people; the appearance ${ }^{1}$; the construction works" [25].

42 Following the NA to BS EN 1990 "criteria should be specified for each project and agreed with the client". The 43 requirements of limit state design may be met by design directly based on probabilistic methods (Annex $\mathrm{C}$ of 44 EN 1990 [25]), or by the partial factor method. The second, is understood to be by far the dominant method used 45 in practice. Using the partial factor method, the designer must verify that limit states are not exceeded. This 46 requirement is summarised in Eq. 1 and Eq. 2:

$$
\begin{gathered}
E_{\mathrm{d}} \leq R_{\mathrm{d}} \\
E_{\mathrm{d}} \leq C_{\mathrm{d}},
\end{gathered}
$$

47 where $E_{d}$ is the design value of effect of an action, $R_{d}$ is the design value of the resistance, whereas $C_{d}$ is the 48 limiting design value of the relevant serviceability criteria. Serviceability criteria, which include deflections and 49 vibrations, are introduced in European design codes but specific constraints (such as deflection limits) are not

\footnotetext{
${ }^{1}$ The term "appearance" is concerned with such criteria as high deflection and extensive cracking, rather than aesthetics.
} 


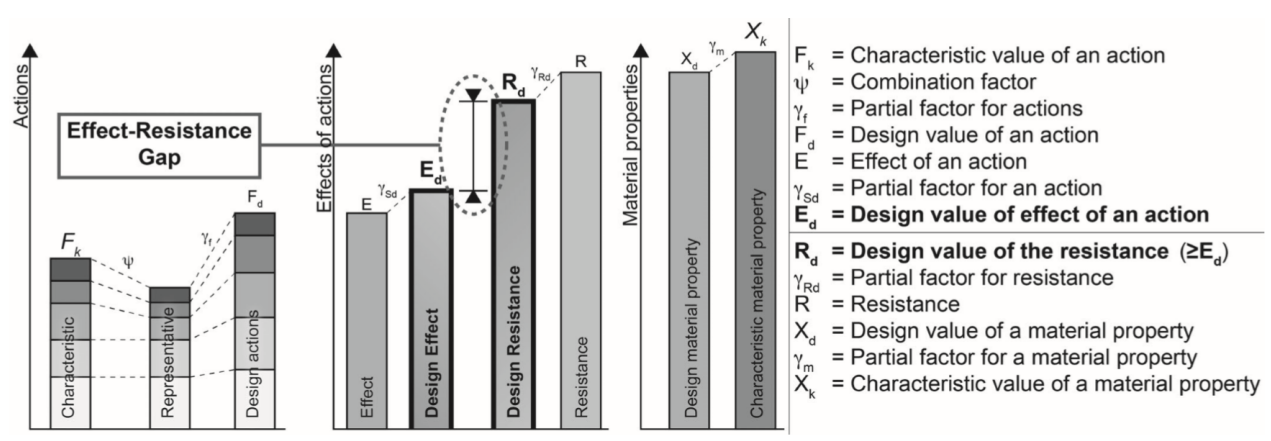

Figure 1: Diagram illustrating the "Effect-Resistance Gap" [26].

but is the scope of the authors' future research.

Less conservative SLS criteria for members that are governed by SLS would reduce materials and hence initial carbon in the structural frame. This brings into question the suitability of the design rules themselves. Since the serviceability criteria determine whether the structure is comfortable and useable and exceeding them would not lead to a structural failure, is it justified that they regularly govern design? One of the results of the MEICON project online survey conducted in 2017 [30] was that even if exceeding SLS is non-compliant with limit state design, designers are comfortable with allowing accepted limits to be exceeded. It should also be highlighted that SLS limits accepted and agreed with the client are usually more conservative than suggested either in structural codes or guidance (e.g. BS EN 1993-1-1 UK NA [31, 32]). This might be a reason why engineers feel comfortable if SLS limits are exceeded. Understanding SLS performance in relation to ULS requirements is essential to understanding how SLS limits affect the use of material within a structure. In order to understand the suitability of serviceability criteria used in the design, based on the case studies included in [27, 24, 33, 34], this paper aims to quantify the embodied carbon consequences of SLS criteria, and establish the true extent to which serviceability is governing design. It focuses on the mass-minimisation of individual members, knowing topology and geometry, as this is the most accessible form of optimisation for structural engineers. For the purpose of this work, a computational tool has been developed. The purpose of this tool was to find the lightest beam from the UB catalogue for a given set of design criteria, whilst also also determining the governing criteria and material utilisation of the optimised design. Output from the tool was verified against third-party calculations. As a result mass savings were found that could be achieved when choosing the lightest non-composite universal beams according to NA BS EN 1993 [31]. Further savings were found under different design assumptions (e.g. relaxing SLS limits as well as decreasing the partial factor for permanent loads reduction from 1.35 to 1.1 or using an average than characteristic steel yield strength).

Apart from the Introduction, this paper consists of five main parts. In section 2 we present the alternative 
methods of structural optimisation indicating which method may provide the greatest material savings. In section 3, SLS limits are presented with with methods of determining them. In this section we also explain the LBM tool operation. In section 4 we verify the LBM tool based on steel floor members from 27 real buildings. In next section we use LBM tool to find potential savings for the designed beams due to optimisation. We discuss mass and carbon savings, both for non-composite beams and a whole structure in the section 6 . Final conclusions were drawn in the last section.

\section{Optimisation}

Baldock [35] highlights three main areas associated with the design of structures where optimisation could occur: 1) topology (optimal number of members and the way they connect); 2) geometry (the optimal length of members); and 3) individual member cross-section sizing. They are listed here in order of decreasing computational complexity, and while a truly optimised solution would consider all three, design tradition [36] and layout requirements originating from the client tend to limit frame geometries seen in practice [37]. The impact of the choice of geometry on embodied carbon was noticed by Dunant et al. [27]. They found no correlation between the building complexity on the mass, cost, the floor technology, and the structural members utilisation. Nevertheless, Dunant et al. [34] found that using a regular grid could have brought $21 \%$ initial (cradle-to-gate) carbon savings in analysed case studies, whereas picking the optimal decking variant could have brought $22 \%$ carbon savings. Once the floor system and beam layout are chosen, initial (cradle-to-gate) carbon savings due to members optimisation can reach 7\%. Despite the mass-minimisation of individual members yielding the lowest savings it is the most accessible form of optimisation for structural engineers and should not be omitted.

From a structural point of view, full use of material occurs when the design value of the effects of actions is equal to the design value of the resistance $\mathrm{UR}_{U L S}=100 \%$ (Equation 1). As presented above, ULS limit does not always govern the structure. Floor beams spanning more than $6-7 \mathrm{~m}$ are usually governed by SLS limits the deflection or the natural frequency [27]. Overall depths for reinforced concrete frame elements are typically governed by deflection as well [38]. From a material efficiency point of view structures should be designed for utilisation ratios of 1.0 but engineers seem reluctant to exceed URs of $0.8[27,11]$. As a result, it can be assumed that at least $20 \%$ of steel mass is not utilised [27]. Intuitively, it appears that the potential mass savings can be obtained according to the Equation 3, where "Maximum UR" is the value closest to 1.0 for either ULS or SLS. However, this is a significant simplification. "Maximum UR" is not necessarily the governing criterion for the lightest solution and therefore "Achievable potential mass saving" does not reflect and therefore Equation 3 does not reflect the true potential mass and carbon savings for a structure. Nevertheless, the previous literature had used Equation 3 and had also assumed that the "Maximum UR" is proportional to the extent to which that criterion 
governed the structure $[27,11]$.

$$
\text { Achievable potential mass saving }(\%)=100 \%-\text { Maximum UR }_{(U L S ; S L S)}(\%)
$$

A steel cross-sections optimisation tool according to material efficiency has been introduced by D'Amico at al. [37]. "Built Environment Efficiency Tool for Low Environmental Externalities" (BEETLE ${ }^{2}$ ) considers "simple" construction, where nominally pinned connections are assumed between elements; hence individual members can be designed and optimised independently from each other and the bearing system of columns and bracings. The tool efficiently calculates the minimum steel mass needed to fulfil safety and serviceability requirements set by design codes but, while it can be used to determine the potential mass savings in a steel frame by comparing an optimised and non-optimised case study, the output is high-level and therefore the significance of different design constraints of the design code is not easily visible.

There is scope to reduce the use of structural steel while conforming to existing design rules. If material savings are calculated based on the "Maximum UR" (3), we find that it reveals little about what criterion governs the lightest solution. Rather than estimating the potential for mass savings based on the "Maximum UR", the load and input data would need to be considered to determine the lightest beam solution that adheres to the design codes; and a more sophisticated analysis required to determine which criterion is critical and limiting the mass of structural beams. For this purpose the Lightest Beam Method (LBM) tool was developed which can optimise cross-sections while the impact of each design constraint remains transparent and the governing criterion is determined [39]. The LBM chooses the lightest beam, from a catalogue of UBs included in "Blue Book" published by SCI [40], in accordance with the European design codes. The input parameters, including those usually defined by the code, are editable such that the user can quickly make changes to the input (particularly in the context of serviceability constraints) and observe the corresponding change in the required mass. LBM allows the user to find steel savings for assumed topology and geometry, and therefore can be used by structural engineers as a accessible form of individual member optimisation.

\section{The Lightest Beam Method (LBM)}

This investigation concerns cross-section optimisation, meaning that decisions such as the chosen floor system and beam layout have already been made. At this stage, the designer needs to select a steel member that meets the minimum performance requirements for a prescribed loading condition (and any other special constraints); as established by design codes. For the purpose of this investigation, members are assumed to be selected from a discrete catalogue of standard Universal Beams (UB) whose properties are given in the SCI "Blue 
Book" [40]. Custom-sized fabricated beams are used in industry, but the UB catalogue used is large enough that meaningful optimisation can occur. To find the impact of SLS limits on initial carbon intensity, a tool was developed to automate member selection according to the Eurocodes. A tool was designed such that for given loading conditions, the lightest UB member compliant with the Eurocodes is chosen. The tool minimises the required section mass according to each design constraint and in turn highlights which constraint is governing the member. The spreadsheet functions by simultaneously calculating the design resistances of each catalogue beam according to each design constraint and determines which beams are valid. As the beams are analysed in isolation, no information on the layout of the frame or the way the beams interact is required; only the beam length and the loading conditions from which design effects can be determined.

\subsection{ULS and SLS limits}

In this paper ULS calculations were made according to the Eurocode 0 [25, 41], Eurocode 1 [29, 42] and Eurocode 3 [43, 31], using all prescribed in codes partial safety factors. SLS concern the functioning of the structure, the comfort of people and appearance, serviceability requirements may vary for different buildings/ structures. The most common serviceability criteria associated with steel frame design are deflection and vibration. The Eurocodes do not prescribe the SLS limits, they might be however suggested in the National Annexes. BS EN 1990 [25] specifies that vertical deflections should be limited to avoid deformations that damage the structure or deformations that affect appearance. The UK National annex for BS EN 1993-1-1 [31] provides suggested limits for non-composite beams (Table 1) that can be calculated according to Equation 4,

Table 1: Recommended deflection limits for non-composite beams from BS EN 1993-1-1 UK NA [31].

\begin{tabular}{lc}
\hline Beam Type & Deflection Limit \\
\hline Cantilevers & Length/180 \\
Beams carrying plaster of brittle finish & Span/360 \\
Other beams (except purlins and sheeting rails) & Span/200 \\
\hline
\end{tabular}

$$
\delta=\frac{5}{384} \frac{w L^{4}}{E I}
$$

where $w$ is uniform load per unit length and is dependent on load case, $L$ the beam span, $E$ the Young's Modulus and $I$ the second moment of area. When considering damage to the structure or finishes, calculations should be made using permanent and variable actions. When considering the comfort of the user, the calculations should be made under variable actions only.

Requirements for vibrations can vary significantly depending on the building use, and while vibration theory can be complex, designers have typically used floor natural frequency as the measure of performance [31]; seeking to avoid resonance with standard human footfall. Natural frequency limits are usually taken as $4 \mathrm{~Hz}$ for simply 
supported condition using permanent loads with $10 \%$ of variable loads [44]. The reduced value of variable load is recommended by Hicks [45] to more appropriately represent an in-service floor system. Smith [44] recommends a simplified design calculation for first mode of vibration, $\mathrm{f}_{1}$ as given in Equation 5 along with a revised minimum frequency of $3 \mathrm{~Hz}$,

$$
f_{1} \approx \frac{18}{\sqrt{\delta}}
$$

where $\delta$ is the maximum deflection due to permanent loads only.

\subsection{LBM assumptions}

For auditability and transparency, an overview of the design constraints considered by the spreadsheets is provided. The calculations of effects and resistances are in accordance with the design codes and classical beam theory. Not all calculations are outlined, but any particular assumptions or special cases are specified. The tool selects beams according to the bending moment, shear capacity, deflection, vibration, lateral torsional buckling.

Fire resistance of beams is omitted from the design as members are assumed to be suitably treated; making fire resistance independent of beam mass [46]. For a given beam the key inputs were: effective beam span length (m), permanent line load $g_{k}\left(\mathrm{kN} / \mathrm{m}\right.$, excluding beam self-weight), variable line load $\mathrm{q}_{\mathrm{k}}(\mathrm{kN} / \mathrm{m})$. Beam self-weight was incorporated into the calculations, but not required as an input since it was taken from the beam catalogue. In addition to the inputs unique to each beam, parameters usually defined by the Eurocodes or National Annexes are available as input variables. Table 2 lists the parameters required for the analysis; with each input populated with typical values. For a given input scenario, the lightest beam from the catalogue of UB members that is compliant with the code was output. The tool also provides supplementary information to be used for analysis - the most noteworthy being governing criteria and utilisation ratios.

Table 2: Tool input parameters populated with typical values.

\begin{tabular}{lc}
\hline Input Variable & Value \\
\hline Permanent Partial Factor, $\gamma_{G}$ & 1.35 \\
Variable Partial Factor, $\gamma_{Q}$ & 1.5 \\
Reduction Factor, $\xi$ & 1 \\
Max Permissible deflection (L/?) & 360 \\
Minimum Fundamental Frequency, $\mathrm{f}_{1}(\mathrm{~Hz})$ & 4 \\
Steel Grade & $\mathrm{S} 355$ \\
Gap between precast units (mm) & 20 \\
Shear area factor, $\eta$ & 1 \\
Partial Factor Resistance of cross-sections, $\gamma_{M 0}$ & 1 \\
Partial Factor Resistance of member to instability, $\gamma_{M 1}$ & 1 \\
Lateral Torsional Buckling Parameter $\lambda_{L T, 0}$ & 0.4 \\
Lateral Torsional Buckling Parameter $\beta$ & 0.75 \\
\hline
\end{tabular}




\subsection{The tool operation}

The methodology in which the tool selects the optimal beam, outputs utilisation ratios and determines the governing criteria is illustrated in the Flow Chart in Figure 2. The Calculations and Engine phases of the tool are illustrated in more detail for each design criterion in Figure 3. The chart describes the equations used to calculate "Design Effects" and then how checks are carried out against "Design Resistances" or "Permissible Values". Calculations for resistance are not detailed but are in accordance with BS EN 1993-1-1 [31]. The equations for "Utilisation Ratio" according to each criterion are also detailed. Owing to developed tool limitation only simply supported, uniformly loaded secondary UB were analysed. The tool takes into account the deformation of the beam, not the deformation of the floor slab.

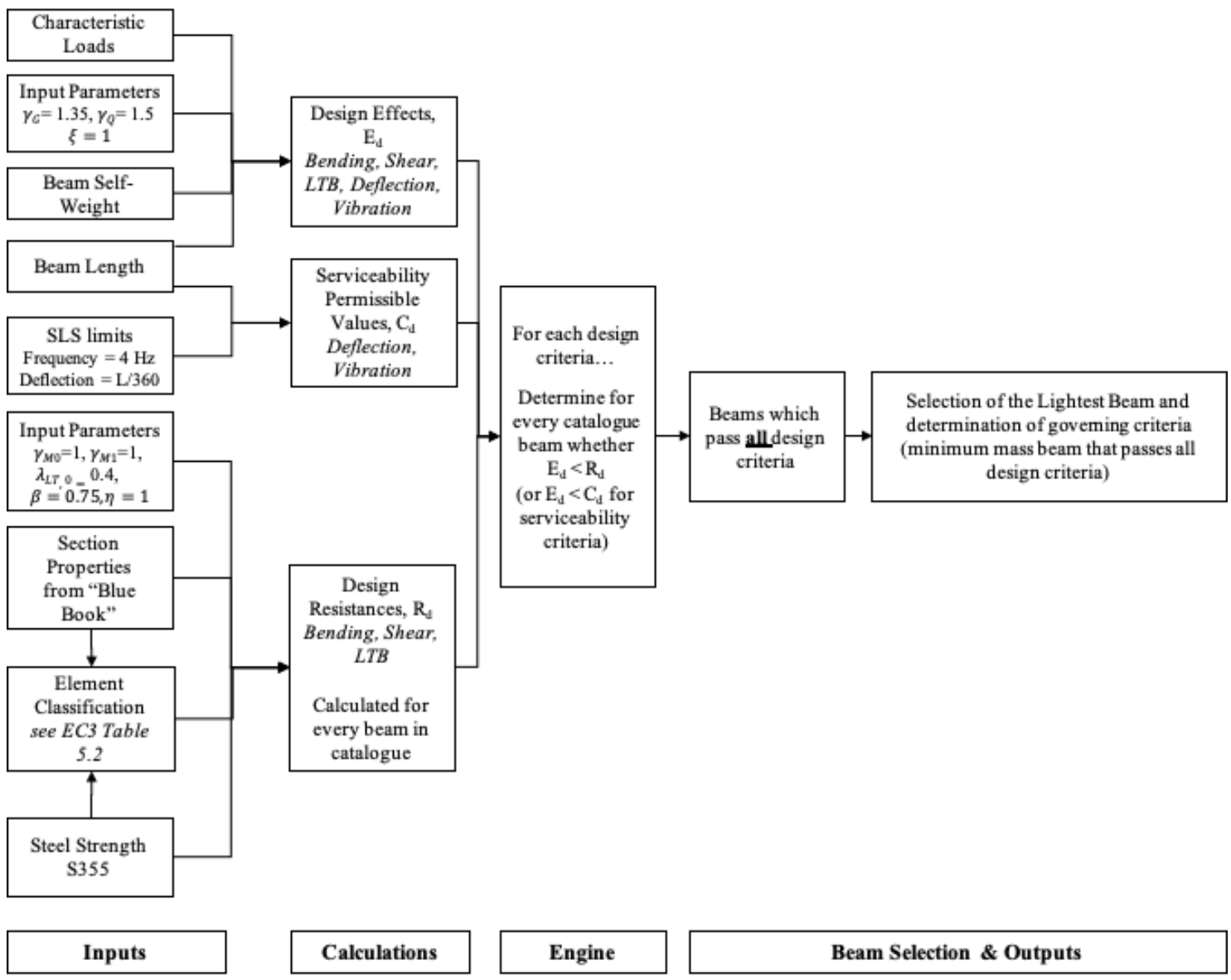

Figure 2: Flow chart illustrating the operation of the developed design tool. 


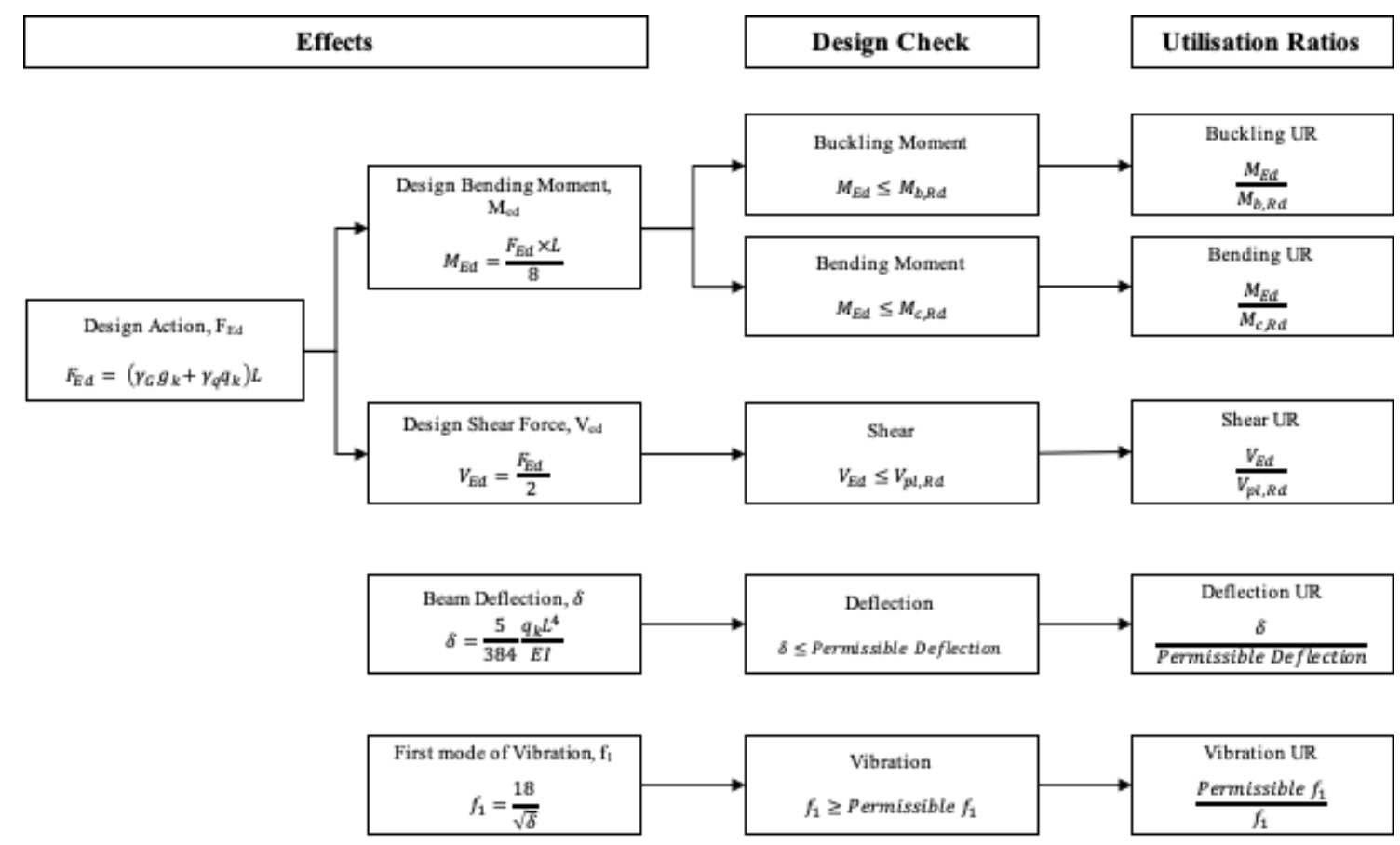

Figure 3: Further detail on the calculations made by the spreadsheets include the UR equations,

$\mathrm{L}=$ Beam length $(\mathrm{m}), \mathrm{E}=$ Young's Modulus of Steel, $\mathrm{g}_{\mathrm{k}}=$ Permanent load per unit length $(\mathrm{kN} / \mathrm{m}), \mathrm{I}=$ Beam second moment of area, $\mathrm{q}_{\mathrm{k}}=$ Variable load per unit length $(\mathrm{kN} / \mathrm{m}), \mathrm{M}_{\mathrm{b}, \mathrm{Rd}}=$ Design Buckling Resistance, $\gamma_{G}=$ Partial factor for permanent loads, $\mathrm{M}_{\mathrm{c}, \mathrm{Rd}}=$ Design Bending Resistance, $\gamma_{Q}=$ Partial factor for variable loads, and $\mathrm{V}_{\mathrm{pl}, \mathrm{Rd}}=$ Design Plastic Shear Resistance. 


\section{LBM tool verification based on literature case studies}

Data taken from [27] was used to verify the LBM tool; consisting of over 3500 floor plate beams from 30 buildings (Table 3), 27 of which were designed and already built. Buildings 28, 29 and 30 were modelled buildings, having the same floor areas, floor layout, using the same assumptions but differed in structural arrangement. From original drawings and correspondence with the Design Consultancy, beam data including type, length, mass and connection type were recorded along with loading details, steel quality and information regarding the overlying floor system. Analysed raw data was exported from Fastrak a steel building design software, used by the Design Consultancy company to design the analysed buildings. For all case studies, approximately two-thirds of the total steel frame mass was in steel members that span horizontally and support the building floor [27]. The floors were usually slabs of reinforced concrete which sit directly supported by "Secondary" steel beams. These secondary steel beams were in turn supported by "Primary" beams running perpendicularly; $90 \%$ of all floor beams were designed as simply supported. The majority of buildings, except 7, 24, 27-30 (designed using EC3 [43]) were designed using BS5950 [47]. Figure 4 shows tonnage of structural frame, including columns, per $\mathrm{m}^{2}$ of building with information on the share of non-composite beams. To understand the diversity of beam types within the dataset, the beams have been split into different categories as given in Table 4. Using the simplification that the "Maximum UR" indicates the governing criterion Dunant et al. [27] determined that serviceability governs in 63\% of beams and $79 \%$ of beams by mass.

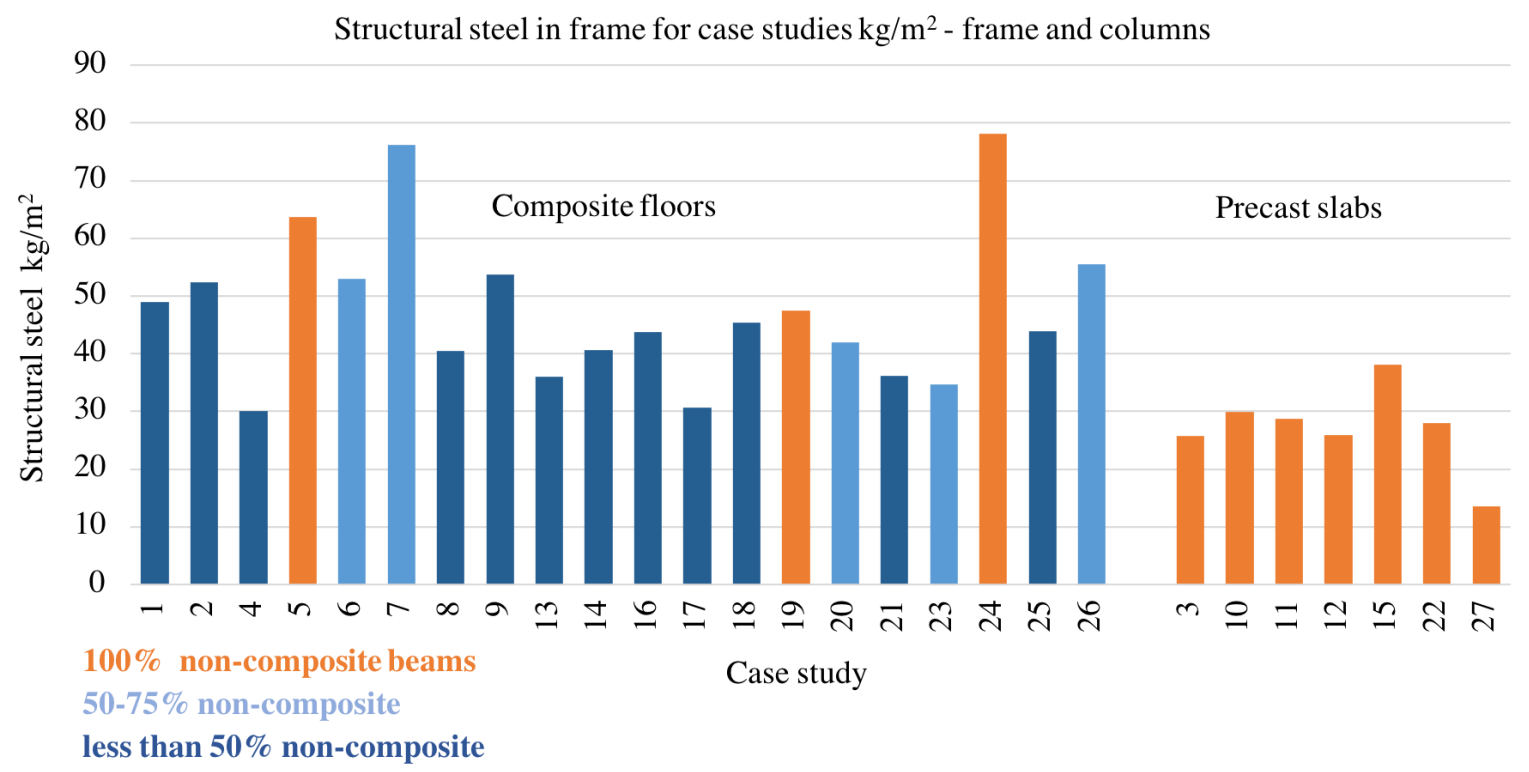

Figure 4: Mass of structural frame per $\mathrm{m}^{2}$ for all case studies. 
Table 3: Overview of the case studies. Sectors are Commercial (C), Education (E), and Model (M). Floor systems are Trapezoidal (T), Pre-cast Decking $(\mathrm{P})$ and Re-entrant decking (R), Superimposed Dead Load (SDL, kN/m²), Floor Live Load (FLL, kN/m²), Partition Allowance (PA, $\mathrm{kN} / \mathrm{m}^{2}$ ). All case studies are from the UK [27].

\begin{tabular}{|c|c|c|c|c|c|c|c|c|c|c|c|}
\hline \multirow{2}{*}{$\begin{array}{r}\text { No. } \\
1\end{array}$} & \multirow{2}{*}{$\begin{array}{l}\text { Type } \\
\text { C }\end{array}$} & \multirow{2}{*}{$\begin{array}{l}\text { Year } \\
2005\end{array}$} & \multirow{2}{*}{$\begin{array}{l}\text { Stage } \\
\text { As Built }\end{array}$} & \multicolumn{2}{|c|}{ Storeys \& High } & \multirow{2}{*}{$\begin{array}{l}\text { Model } \\
\text { None }\end{array}$} & \multirow{2}{*}{$\begin{array}{l}\text { System } \\
\mathrm{T}\end{array}$} & \multirow{2}{*}{$\begin{array}{l}\text { SDL } \\
1.25\end{array}$} & \multirow{2}{*}{$\begin{array}{c}\text { FLL } \\
3.5\end{array}$} & \multirow{2}{*}{$\begin{array}{l}\mathrm{PA} \\
1.0\end{array}$} & \multirow{2}{*}{$\begin{array}{l}\text { Steel } \\
\text { Grade }\end{array}$} \\
\hline & & & & 13 & 50.0 & & & & & & \\
\hline 2 & $\mathrm{C}$ & 2009 & Tender & 17 & 66.0 & None & $\mathrm{R}$ & 0.85 & 3.5 & 1.0 & S355 \\
\hline 3 & $\mathrm{C}$ & 2006 & Construction & 5 & 17.5 & None & $\mathrm{P}$ & 0.95 & 2.5 & 1.0 & S275 \\
\hline 4 & $\mathrm{C}$ & 2013 & Construction & 3 & 12.0 & None & $\mathrm{R}$ & 1.50 & 4.0 & 0.0 & S355 \\
\hline 5 & $\mathrm{C}$ & 2010 & Construction & 6 & 21.8 & None & $\mathrm{R}$ & 0.80 & 4.0 & 1.0 & S275 \\
\hline 6 & $\mathrm{C}$ & 2008 & Construction & 3 & 11.0 & None & $\mathrm{R}$ & 0.75 & 2.5 & 1.0 & S275 \\
\hline 7 & $\mathrm{C}$ & 2016 & Preliminary & 10 & 45.0 & Unknown & $\mathrm{T}$ & 0.85 & 4.0 & 0.0 & S355 \\
\hline 8 & $\mathrm{C}$ & 2006 & Construction & 5 & 23.3 & None & $\mathrm{T}$ & 0.85 & 3.0 & 1.0 & S355 \\
\hline 9 & $\mathrm{C}$ & 2001 & Construction & 3 & 11.4 & None & $\mathrm{T}$ & 1.00 & 4.0 & 1.0 & S275 \\
\hline 10 & E & 2016 & As Built & 3 & 11.8 & Full Frame & $\mathrm{P}$ & 3.10 & 3.0 & 0.0 & S355 \\
\hline 11 & E & 2017 & Preliminary & 2 & 8.0 & Full Frame & $\mathrm{P}$ & 2.50 & 3.0 & 1.0 & S355 \\
\hline 12 & E & 2017 & Tender & 2 & 9.0 & Full Frame & $\mathrm{P}$ & 3.90 & 3.0 & 1.0 & S355 \\
\hline 13 & E & 2012 & Construction & 3 & 11.6 & Full Frame & $\mathrm{T}$ & 2.70 & 3.0 & 1.0 & S355 \\
\hline 14 & E & 2016 & Construction & 2 & 7.7 & Full Frame & $\mathrm{R}$ & 0.50 & 3.0 & 1.0 & S355 \\
\hline 15 & E & 2006 & Construction & 3 & 9.3 & None & $\mathrm{P}$ & 2.00 & 4.0 & 0.0 & S275 \\
\hline 16 & E & 2013 & Construction & 2 & 7.6 & Full Frame & $\mathrm{T}$ & 1.50 & 3.0 & 1.0 & S355 \\
\hline 17 & E & 2005 & Construction & 3 & 11.2 & None & $\mathrm{R}$ & 0.85 & 3.0 & 1.0 & S275 \\
\hline 18 & E & 2013 & Tender & 5 & 11.2 & None & $\mathrm{R}$ & 0.95 & 3.0 & 1.0 & S275 \\
\hline 19 & E & 2016 & Construction & 2 & 6.3 & Full Frame & $\mathrm{T}$ & 0.30 & 2.5 & 1.0 & S275 \\
\hline 20 & E & 2014 & Construction & 3 & 12.6 & Full Frame & $\mathrm{T}$ & 0.45 & 3.0 & 1.0 & S355 \\
\hline 21 & E & 2013 & Construction & 3 & 11.6 & Full Frame & $\mathrm{T}$ & 0.48 & 3.0 & 1.0 & S355 \\
\hline 22 & E & 2014 & Construction & 2 & 8.7 & None & $\mathrm{P}$ & 0.48 & 3.0 & 1.0 & S355 \\
\hline 23 & E & 2016 & Tender & 3 & 11.4 & Full Frame & $\mathrm{T}$ & 2.00 & 3.0 & 1.0 & S355 \\
\hline 24 & $\mathrm{C}$ & 2014 & Construction & 1 & 5.9 & Unknown & $\mathrm{T}$ & 1.80 & 5.0 & 0.0 & S355 \\
\hline 25 & $\mathrm{C}$ & 2016 & Tender & 13 & 54.9 & Unknown & $\mathrm{R}$ & 1.45 & 4.0 & 1.0 & S355 \\
\hline 26 & E & 2018 & Tender & 4 & 17.2 & Full Frame & $\mathrm{T}$ & 2.60 & 3.0 & 1.0 & S355 \\
\hline 27 & $\mathrm{C}$ & 2016 & Construction & 2 & 5.7 & None & $\mathrm{P}$ & 2.70 & 3.0 & 0.0 & S355 \\
\hline 28 & M & - & - & 8 & 26.8 & Floor Plate & $\mathrm{T}$ & 0.85 & 4.0 & 1.0 & S355 \\
\hline 29 & M & - & - & 8 & 26.8 & Floor Plate & $\mathrm{T}$ & 0.85 & 4.0 & 1.0 & S355 \\
\hline 30 & M & - & - & 8 & 26.8 & Floor Plate & $\mathrm{T}$ & 0.85 & 4.0 & 1.0 & S355 \\
\hline
\end{tabular}

\subsection{Limitations of the data}

The raw data required processing to be compatible with the prepared spreadsheets. It was also incomplete in parts and all the assumptions made by Fastrak, such as concrete strength classes, had not been recorded. For analysing the data as a case study, it was not vital that exactly the same assumptions were made as long as sufficient input data was available to the Excel spreadsheets. In seeking to verify the spreadsheet output against Fastrak's, however, the same assumptions would need to be made for the results to align. The first key set of unavailable data was beam line loads. Originally beam layout was manually entered into Fastrak along with loading per unit area; which allowed Fastrak to determine loads on the beams. The uniform line loads required by the spreadsheets to analyse secondary beams were therefore not provided and needed to be interpreted from the available data. Furthermore, there were no data on the serviceability limits to which the beams were designed. Like the beam loads, the prescribed permissible values for deflection and vibration needed to be interpreted from Fastrak's UR output. A certain amount of trial and error was required to determine the limits which had been used. 
Table 4: Overview of the case study beams.

\begin{tabular}{|c|c|c|c|}
\hline Measure & No. of beams & Mass (kg) & Proportion by mass \\
\hline Total Beams & 3626 & $1,524,228$ & - \\
\hline \multicolumn{4}{|l|}{ Floor System } \\
\hline Decking - Trapezoidal & 2262 & $1,094,253$ & $71.8 \%$ \\
\hline Decking - Re-Entrant & 773 & 300,998 & $19.7 \%$ \\
\hline Precast planks & 591 & 128,977 & $8.5 \%$ \\
\hline \multicolumn{4}{|l|}{ Steel grade } \\
\hline $\mathrm{S} 275$ & 710 & 227,199 & $14.9 \%$ \\
\hline S355 & 2916 & $1,297,029$ & $85.1 \%$ \\
\hline \multicolumn{4}{|l|}{ Beam End Conditions } \\
\hline Fix/Fix & 32 & 17,386 & $1.1 \%$ \\
\hline Pin/Pin & 3227 & $1,374,815$ & $90.2 \%$ \\
\hline Pin/Fix & 181 & 104,415 & $6.9 \%$ \\
\hline Fix/Free & 186 & 27,612 & $1.8 \%$ \\
\hline \multicolumn{4}{|l|}{ Beam Types } \\
\hline Primary & 1012 & 526,598 & $34.6 \%$ \\
\hline Secondary & 1909 & 913,130 & $59.9 \%$ \\
\hline Core/Trimmer/Tie & 705 & 84,500 & $5.5 \%$ \\
\hline Composite & 1542 & $1,008,873$ & $66.2 \%$ \\
\hline Non-Composite & 2084 & 515,355 & $33.8 \%$ \\
\hline Universal Beam & 3061 & 512,030 & $33.6 \%$ \\
\hline Fabricated & 565 & $1,012,198$ & $66.4 \%$ \\
\hline \multicolumn{4}{|c|}{ Governing Criteria (According to maximum UR) } \\
\hline Deflection & 1202 & 441,505 & $29.0 \%$ \\
\hline Natural frequency & 1080 & 759,301 & $49.8 \%$ \\
\hline Vertical Shear & 183 & 23,880 & $1.6 \%$ \\
\hline Bending Moment & 1161 & 299,542 & $19.6 \%$ \\
\hline
\end{tabular}

\subsubsection{Determining beam line loads}

In order to run the LBM tool on each beam, loading conditions were determined. The raw case study data detailed loading in terms of a general live load, a general superimposed dead load (SDL), partition loading and floor weight all measured per unit floor area. How these loads translated to a uniform line load on the secondary supporting beams needed to be determined from the available information. Design drawings were available; and the layout of the beams could have been used to determine line loads directly. As an automated and faster alternative, however, the loads were calculated indirectly by reverse-engineering the calculations made by Fastrak. The permanent and variable loads per unit area were calculated according to Equations 6 and 7 for each case study.

$$
\text { Permanent Load (less beam self weight) } k N / \mathrm{m}^{2}=\text { General SDL + Floor Weight }
$$


For non-composite beams, the provided raw data on "Live Deflection (mm)" was used to calibrate the variable load. Once the variable load was found, the tool determined the deflection for each beam. The calculated deflection was compared with the deflection calculated by Fastrak, and since deflection is proportional to load, the test variable line load was scaled accordingly to match the deflections. The provided raw data on "Dead Deflection $(\mathrm{mm})$ " was used to scale the variable load to determine the permanent line load. Checks were carried out to confirm the ratio of variable to permanent line load matched the ratio of loads per unit area as in Equations 6 and 7. The slight discrepancies were accounted to the self-weight of the beam having been omitted. The point loads for primary beams could not be determined in an automated fashion as detailed information on the location of applied point loads was not available. As a result, line loads were determined for all for all secondary beams. It should be noted that the accuracy of loads determined for beams with small deflections was limited by rounding errors in Fastrak's output for deflection. However, the verification stage was able to omit any outliers. The uniform vertical loading eliminates the requirement to consider combination of actions for strength criteria [20] and the design action per unit beam length was determined according to Equation 8,

$$
\text { Design action per unit length, } F_{d}=\gamma_{G} g_{k}+\gamma_{Q} q_{k}
$$

where $g_{k}$ is the permanent line load, $q k$ the variable line load and $\gamma_{G}$ and $\gamma_{Q}$ the partial factors for permanent and variable loads respectively. Hence, looking at the vertical uniform loads on nominally pinned secondary beams in steel frame structures, it is possible to optimise each member in isolation and investigate the relative influence of each design constraint.

\subsubsection{Interpreting serviceability limits}

As no information on the deflection and vibration limits used for design were recorded, they needed to be interpreted from Fastrak's UR outputs. The calculations used by Fastrak differed from the limits included in [31] and [44] and therefore were interpreted via simulation. Considering the non-composite beams, while the UK National Annex BS EN 1993-1-1 [31] states that deflection calculations should consider characteristic variable loads only, Fastrak calculated deflection UR according to Equation 9. Fastrak considered variable loads in isolation as well as variable and permanent loads combined, with limits of L/360 and L/250 respectively. Significantly, these two deflection limits were considered for all simply supported non-composite beams.

$$
\text { Deflection } \mathrm{UR}_{\text {NonComp }}=\operatorname{Max}\left(\frac{\text { Variable } \delta}{\text { Length } / 360}, \frac{\text { Permanent } \delta+\text { Variable } \delta}{\text { Length } / 250}\right)
$$


Similarly for vibration, Fastrak does not use the simplified method recommended by Smith [44] but instead utilises the more traditional approach including variable loads. The calculation for vibration UR used by Fastrak is given in Equation 10 with a minimum fundamental frequency of $4 \mathrm{~Hz}$,

$$
\text { Vibration } \mathrm{UR}_{\text {NonComp }}=4 \mathrm{~Hz} / \frac{18}{\sqrt{1 \times \text { Permanent } \delta+0.1 \times \text { Variable } \delta}}
$$

\subsubsection{Verification results}

Having determined the beam line loads and the serviceability criteria used for the case study beams, the developed tool was used to calculate the utilisation ratios of each beam according to each design criterion. These values could then be compared to the output from Fastrak in order to verify the spreadsheets' function. For verification purposes, the URs calculated by Fastrak are assumed to be correct and henceforth referred to as "Fastrak's output". The tool's output for design effects and resistances were previously verified against worked examples from literature. Comparing results against Fastrak therefore instead served as a test for the way the input data has been interpreted and a check for the way the tool had been set up to mimic the original case study design; such as the loads and serviceability measures assumed. The beams that align with the results from Fastrak can then be taken as correctly modelled and carried forward to the next stage of the investigation. The 603 non-composite beams with loading data were inserted into the tool and the utilisation ratios according to bending, shear, deflection and vibration were compared to Fastrak's results. The deviations of the tool's output from Fastrak are plotted as cumulative frequency graphs in Figure 5. Positive deviation values indicate where the tool has calculated a lower UR than Fastrak. Observing each criterion in isolation, it can be observed that URs closely align for the majority of beams. As the loads were calibrated according to deflections it is unsurprising that the deflection URs match closely. As vibration is a function of deflections it follows that the vibration calculations align well. A very small number of beams resulted in large deviations, for which the cause was unclear. It is possible that the serviceability limits for these beams differed from the majority and the information was not captured in the data.

Verification matched well with SLS criteria but the tool had outputted ULS UR relatively low for around 20\% of beams (Figure 5). The results show that 441/603 beams matched all criteria within 5\%. From Case Studies 26, 28, 29 30, only 5 out of 117 beams matched all criteria within 5\%. Raw data for this case studies marked these beams as S355 but if the yield strength for this case studies is changed to S275, the match is more precise, giving 521/603 beams (Figure 6). Despite the steel grade S275 for Case Studies 26, 28, 2930 providing a better solution, the input steel grade was not changed from S355 in order to be consistent with the raw data. Overall, 441 beams aligned according to all criteria and were considered valid. Table 5 presents steps that reduces the number of non-composite beam due to LBM tool limitations. Table 9 presents percentage of beams that were analysed 


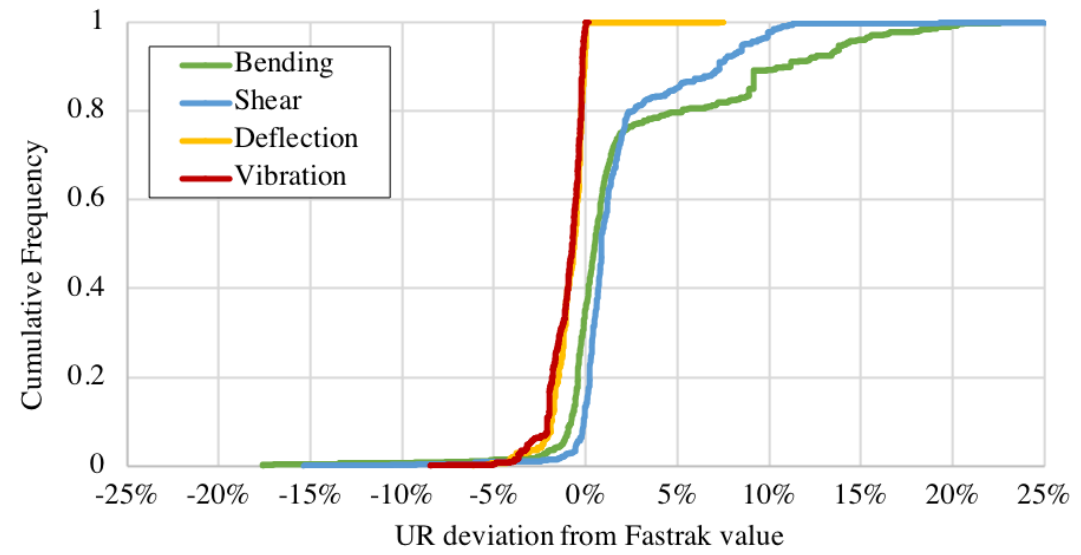

Figure 5: Cumulative frequency plot comparing UR output from tool and Fastrak for non-composite beams. 441/603 beams matched all criteria within $5 \%$.

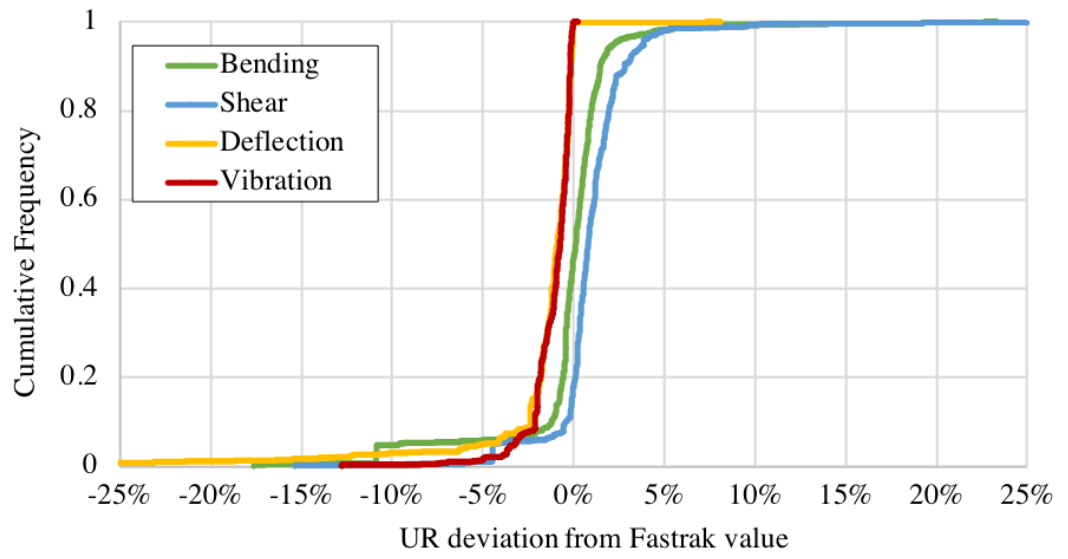

Figure 6: Cumulative frequency plot comparing UR output from tool and Fastrak for non-composite beams using lower steel grade, 521/603 beams matched all criteria within $5 \%$.

from each case study. Case studies 1, 2, 6, 18, 25 were excluded as they did not have beams fulfilling the criteria. Model buildings $(28,29$ and 30) were also excluded.

Table 5: Non-Composite Analysis Summary.

\begin{tabular}{lccc}
\hline Stage & No. of beams & Units $(\mathrm{kg})$ & \% of all beam mass \\
\hline Raw data & 3626 & $1,524,228$ & $100 \%$ \\
Non-Composite & 817 & 190,353 & $12.5 \%$ \\
Catalogue beams & 603 & 133,345 & $8.7 \%$ \\
Verification & 441 & 96,301 & $6.3 \%$ \\
\hline
\end{tabular}




\section{Case studies LBM optimisation}

After determining the input variables necessary to analyse the case study beams and verified them, a series of simulations were carried out. The first set of simulations involved recreating the original design criteria and running the tool to optimise the members seeking to calculate potential mass savings and governing criteria (Simulations 1) and then use the same serviceability criteria as Simulation 1, but for different input parameters (Simulations 5, 7). The next set of simulations involved re-selecting beams under the same loading conditions but varying other input parameters (Simulations 2, 3, 4, 6, 8).

\subsection{Simulation 1 - Optimisation of the members in accordance with original case studies}

A simulation (S1) that optimises the members in accordance with the original case study design constraints. In addition to the established serviceability criteria, the input constants for the non-composite are displayed in Table 6.

Table 6: Constant inputs for the non-composite beams matching the original design criteria.

\begin{tabular}{lc}
\hline Input Variable & Value \\
\hline Permanent Partial Factor, $\gamma_{G}$ & 1.35 \\
Variable Partial Factor, $\gamma_{Q}$ & 1.5 \\
Reduction Factor, $\xi$ & 1 \\
$\mathrm{E}_{\text {steel }}, \mathrm{GPa}$ & 210 \\
Shear area factor, $\eta$ & 1 \\
Partial Factor Resistance of cross-sections, $\gamma_{M 0}$ & 1 \\
Partial Factor Resistance of member to instability, $\gamma_{M 1}$ & 1 \\
Lateral Torsional Buckling Parameter $\lambda_{L T, 0}$ & 0.4 \\
Lateral Torsional Buckling Parameter $\beta$ & 0.75 \\
\hline
\end{tabular}

\subsection{Simulation 2 - alternative SLS criteria}

Simulation 2 (S2) relaxed serviceability to less strict criteria seen in literature. For non-composite beams this meant deflection limits were altered to match the suggested values in BS-EN 1993-1-1 UK National Annex [31] and vibration criteria adapted to Smith's [44] recommendation. Therefore, the changes to the tool's input were as follows:

- Deflection limit changed to L/360 for deflections calculated using variable loads only

- Fundamental natural frequency minimum value to $4 \mathrm{~Hz}$; calculated according to permanent load deflections only

\subsection{Simulation 3 - impact of alternative criteria - vibration limits}

In Simulation 3 (S3), compared to Simulation 2 (S2), only the minimum fundamental frequency limit has changed from $4 \mathrm{~Hz}$ to $3 \mathrm{~Hz}$, as recommended in SCI P354 [48]. 


\subsection{Simulation 4 - impact of alternative criteria - more stricter deflection limits}

While more relaxed serviceability criteria have been investigated, there are certain scenarios where stricter constraints are required; such as in hospital operating theatres or beams supporting glass facades. To investigate the effect of stricter conditions, the most extreme deflection criteria suggested by Eurocode National Annexes is considered. The Finnish National Annex for BS EN 1990 sets a limit of L/400 for total deflection due to variable and permanent loads. Simulation 4 used this deflection criterion with Vibration matching the original design (that used in Simulation 1)

\subsection{Simulations 5-8 - variation of input constants}

The developed tools are not limited to analysing the impact of serviceability criteria. There is scope to vary an array of input constants, usually prescribed by the code or elsewhere, that have the potential to impact embodied energy. Four additional experiments were run with altered input constants - each justified by third-party research including changes to steel yield strength and partial factors. The first (Simulation 5 and 6) constant considered was the yield strength of steel. Beams are classified as a certain yield strength category; the value taken in design calculations is prescribed by the code [31] and decreases with the nominal thickness of the element. Melcher [49] carried out statistical analysis on steel samples determining an average yield strength for S355 steel of $402 \mathrm{MPa}$ and evaluating the true characteristic value for $95 \%$ confidence as $346 \mathrm{MPa}$. As an extreme test for the effect of an altered value, a simulation was run with yield strengths equal to average rather than characteristic values. No statistical data was available for S275 steel, but it was scaled based of Melcher's results to give a value of 310 $\mathrm{MPa}$. The test was run twice using different serviceability criteria, altering the set ups used in Simulations 1 and 3 respectively, and presented as Simulations 5 and 6.

The second input parameter with potential to greatly affect embodied energy is the partial factor. Numerous studies look into the derivation of partial factor values. Reliability verification of the partial factor method in steel structures was carried out by Kala [50]. A probabilistic risk assessment of reliability concludes that the target standard for reliable design [25] requires partial factors due to variable and permanent loads of 1.5 and 1.1 respectively. The tool was therefore run at this lower value of $\gamma_{G}$, again altering the set up used for Simulations 1 and 3, in Simulations 7 and 8.

\subsection{Results of the beam optimisation}

Calculated mass savings are presented in Table 7, whereas comparison of mass savings over original noncomposite beams for different input constants and serviceability criteria are shown on Figure 7. It has been shown that member optimisation is dependent on design criteria and that serviceability can in certain cases be limiting. Notably, the relative importance of the prescribed design values and serviceability limits is dwarfed by the savings 
${ }_{347}$ seen when simply designing to the limit of the code. Referring to Figure 7, recreating the original design criteria 348 in Simulation 1 led to savings for non-composite components of $26.5 \%$ - which is $8.6 \%$ lower than the savings ${ }_{349}$ predicted by the "Maximum UR" method (Eq. 3, Table 8). Higher savings were found for the LBM (Simulation 2) $350-28.7 \%$. The greatest savings, of $34.5 \%$, were found for lower natural frequency assumptions $(3 \mathrm{~Hz})$ and relaxed 351 deflection constraints, combined with using as an assumption an average than characteristic steel yield stress 352 (Simulation 6).

Table 7: Results of the LBM optimisation.

\begin{tabular}{|c|c|c|c|c|c|c|c|}
\hline \multirow{2}{*}{ Beam Type } & \multicolumn{2}{|c|}{ Total Mass Savings } & \multicolumn{5}{|c|}{$\begin{array}{c}\text { Governing Criteria } \\
\text { Proportion of beams by mass }\end{array}$} \\
\hline & Absolute (kg) & $\%$ & Bending & Shear & Deflection & Vibration & Buckling \\
\hline $\begin{array}{c}\text { Simulation } \mathbf{1} \\
\text { original design constraints }\end{array}$ & 25,533 & $26.5 \%$ & $52.5 \%$ & $0.0 \%$ & $30.6 \%$ & $14.8 \%$ & $2.1 \%$ \\
\hline $\begin{array}{c}\text { Simulation } 7 \\
\gamma_{G}=1.1 \\
\text { an increase of } 0.5 \% \text { from } \mathrm{S} 1\end{array}$ & 25,966 & $27.0 \%$ & $28.4 \%$ & $0.0 \%$ & $53.1 \%$ & $16.3 \%$ & $2.1 \%$ \\
\hline $\begin{array}{c}\text { Simulation } 5 \\
\text { Av. yield strength } \\
\text { an increase of } 0.9 \% \text { from S1 }\end{array}$ & 26,403 & $27.4 \%$ & $23.2 \%$ & $0.0 \%$ & $58.2 \%$ & $16.4 \%$ & $2.1 \%$ \\
\hline $\begin{array}{l}\text { Simulation } 2 \\
\text { alternative design constraints } \\
\text { deflection using variable loads }\end{array}$ & 27,621 & $28.7 \%$ & $69.0 \%$ & $0.0 \%$ & $8.5 \%$ & $19.7 \%$ & $2.9 \%$ \\
\hline $\begin{array}{c}\text { Simulation } 3 \\
\text { vibration }=3 \mathrm{~Hz} \\
\text { an increase of } 2.0 \% \text { from S2 }\end{array}$ & 29,569 & $30.7 \%$ & $87.6 \%$ & $0 \%$ & $9.1 \%$ & $0.7 \%$ & $2.6 \%$ \\
\hline $\begin{array}{c}\text { Simulation } 8 \\
\gamma_{G}=1.1 \\
\text { an increase of } 5.2 \% \text { from S3 } \\
\end{array}$ & 32,600 & $33.9 \%$ & $83.8 \%$ & $0.0 \%$ & $11.3 \%$ & $2.2 \%$ & $2.8 \%$ \\
\hline $\begin{array}{c}\text { Simulation } 6 \\
\text { Av. yield strength } \\
\text { an increase of } 5.8 \% \text { from S3 }\end{array}$ & 33,269 & $34.5 \%$ & $80.3 \%$ & $0.0 \%$ & $15.1 \%$ & $1.7 \%$ & $2.9 \%$ \\
\hline $\begin{array}{c}\text { Simulation } 4 \\
\text { deflection L/400 }\end{array}$ & 12,127 & $12.6 \%$ & $2.3 \%$ & $0.0 \%$ & $97.5 \%$ & $0.0 \%$ & $0.3 \%$ \\
\hline
\end{tabular}




\section{Discussion}

\subsection{Steel savings for analysed steel beams}

The aim of this paper was to investigate the extent to which serviceability is governing non-composite UB beams and the corresponding impact on initial embodied carbon. It was observed that altering certain input constants for non-composite universal beams leads to minimal additional mass savings. Table 7 and Figure 7 summarise the mass savings that could be achieved over the original design due to altered serviceability requirements and other inputs. The results of stricter serviceability criteria from Simulation 4 are included for reference.

The analysis shows that optimisation to a full code compliance according to the original design constrains (Simulation 1) can bring $26.5 \%$ of mass savings. Additional $4.2 \%$ mass savings could be achieved if deflection is calculated using variable loads (Simulation 2). When comparing S2 to S1 it was found that the proportion of beams governed by serviceability falls from $47.5 \%$ to $30.6 \%$ by mass; with a transition from deflection to vibration in $\mathrm{S} 2$.

Simulation 3, which used deflection limits suggested in the UK National Annex (L/360 for deflections calculated using variable loads only) with a natural frequency reduction to $3 \mathrm{~Hz}$, according to SCI P354 [48], yielded mass savings greater still. With these altered criteria, bending governs the majority of non-composite beams. Hence, with the serviceability criteria recommended by the UK National Annex and SCI publications, deflection governs less than $10 \%$ of beams by mass and vibration almost none. The difference between the mass savings of S1 and S3 could be interpreted as there being up to $11.3 \%$ additional mass in a floor plate not to provide reliability against collapse, but to improve the serviceability performance above published acceptable levels. The other extreme of serviceability criteria tested in Simulation 4 (deflection L/400), yielded less than half the savings seen with the relaxed constraints of Simulation 3. Deflection governs almost all beams. The additional savings realised by the altered input constants are larger in the relaxed serviceability cases since both partial factor for permanent loads and yield strength of steel affect the ULS calculations but not the SLS calculations. It follows that if more beams are governed by ULS then the relative mass savings from the altered input constants will be higher.

It is evident that relatively substantial changes in input constants can lead to minimal additional mass savings when designing to full code compliance. The change in yield strength particularly is extreme and the average value assumed does not satisfy code reliability yet the impact on mass is small. However, the specific changes tested are representative of a broader phenomenon relating to input constants: namely, the mass savings realised by the altered constants are limited as other criteria (in this case SLS) start to govern. Taking yield strength change as an example, the proportion of beams governed by SLS shifts from $47.5 \%$ to $76.7 \%$ between Simulations 1 and 5 . The 


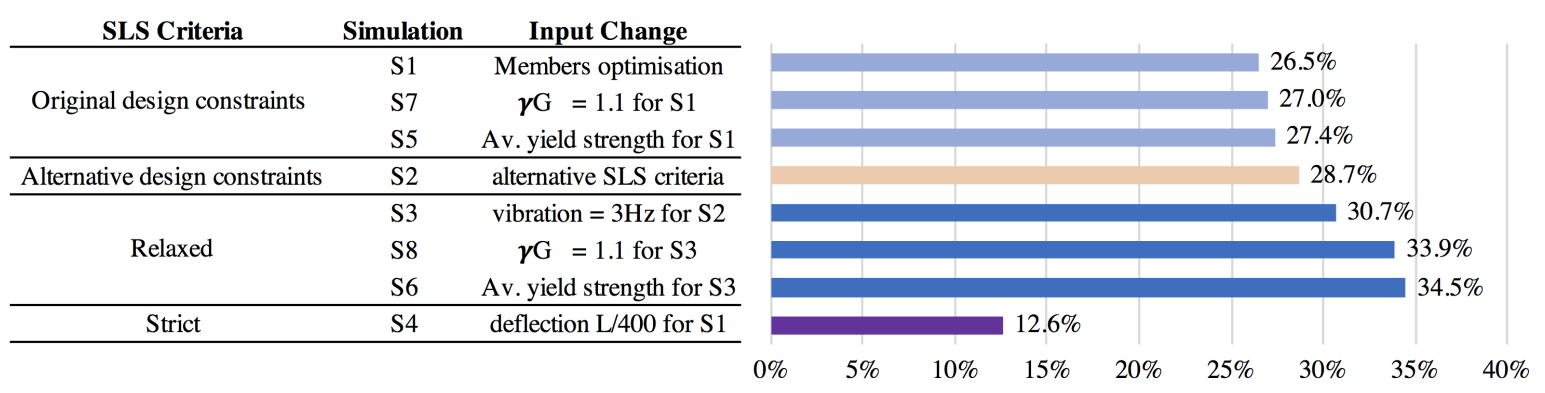

Figure 7: Comparison of mass savings over original non-composite beams for different input constants and serviceability criteria. sure all design decisions are properly considered and justified.

Table 8: Potential in mass savings determined by Dunant at al. [27] according "Maximum UR" method (Equation 3).

\begin{tabular}{|c|c|c|c|c|c|c|c|c|}
\hline \multirow{2}{*}{$\begin{array}{c}\text { Beam } \\
\text { Type }\end{array}$} & \multirow{2}{*}{$\begin{array}{l}\text { No. of } \\
\text { beams }\end{array}$} & \multirow{2}{*}{$\begin{array}{c}\text { Mass } \\
(\mathbf{k g})\end{array}$} & \multirow{2}{*}{$\begin{array}{c}\text { Share } \\
(\%)\end{array}$} & \multicolumn{4}{|c|}{ Governing criterion by mass of beams } & \multirow{2}{*}{$\begin{array}{l}\text { Av. potential mass } \\
\text { savings }(\%)\end{array}$} \\
\hline & & & & Bending & Shear & Deflection & Vibration & \\
\hline $\begin{array}{c}\text { Non-Composite } \\
\text { UB } \\
\text { analysed further using LBM }\end{array}$ & 441 & 96,301 & $6 \%$ & $20.3 \%$ & $1.05 \%$ & $16.6 \%$ & $62.1 \%$ & $35.1 \%$ \\
\hline $\begin{array}{c}\text { Non-Composite } \\
\text { UB } \\
\text { the rest }\end{array}$ & 1550 & 371,812 & $24 \%$ & $27 \%$ & $3 \%$ & $21 \%$ & $49 \%$ & $34 \%$ \\
\hline $\begin{array}{c}\text { Non-Composite } \\
\text { FB } \\
\text { the rest }\end{array}$ & 93 & 47,242 & $3 \%$ & $21 \%$ & $2 \%$ & $14 \%$ & $63 \%$ & $37 \%$ \\
\hline $\begin{array}{c}\text { Composite } \\
\text { UB }\end{array}$ & 1070 & 547,615 & $36 \%$ & $15 \%$ & $1 \%$ & $38 \%$ & $46 \%$ & $34 \%$ \\
\hline $\begin{array}{c}\text { Composite } \\
\text { FB }\end{array}$ & 472 & 461,257 & $30 \%$ & $17 \%$ & $1 \%$ & $28 \%$ & $54 \%$ & $33 \%$ \\
\hline Sum & 3,626 & $1,524,228$ & $100 \%$ & & & & & \\
\hline
\end{tabular}

\subsection{Global steel savings for provided case studies}

The results show that the greater mass savings can be achieved by choosing the lightest UB with full code compliance. Table 9 highlights savings that can be achieved for the analysed case study non-composite beams using the LBM, a) for deflection limit L/360 for variable loads and natural frequency of $4 \mathrm{~Hz}$ calculated according to permanent load deflection (Simulation 2 - S2), b) with an additional assumption of average rather than characteristic steel yield strength (Simulation 6 - S6). 
It should be noted that the simulations did not include all beams from all case studies; however for two of the case studies the analysed beams represented $2 / 3$ of all beams by mass. For 8 additional case studies more than $25 \%$ of beams by mass were represented. Hence, the simulation results can be used to assess the potential mass savings for buildings directly with high non-composite beam share.

To find savings for all beams ( $E C$ ), a combination of LBM (for non-composite secondary beams) and mass savings using "Maximum UR" method (for the rest of beams, Table 8, [27]) was used. Results in \% and tonnes savings are presented on Figures 8 and 9 respectively. Max describes the additional savings achieved for noncomposite beams from Simulation 6. Savings were calculated under the assumption, that the superimposed dead load from slabs does not change.

Table 9: Share of non-composite beams for case studies with computed savings.

\begin{tabular}{|c|c|c|c|c|c|c|c|}
\hline $\begin{array}{l}\text { Case } \\
\text { study }\end{array}$ & $\begin{array}{c}\text { Weight of } \\
\text { all beams } \\
{[\mathrm{kg}]}\end{array}$ & $\begin{array}{l}\text { No. of } \\
\text { all beams }\end{array}$ & $\begin{array}{l}\text { No. of beams } \\
\text { after verification }\end{array}$ & $\begin{array}{c}\text { Weight after } \\
\text { verification } \\
{[\mathrm{kg}]}\end{array}$ & $\begin{array}{c}\text { The share } \\
\text { of the original } \\
\text { structure }\end{array}$ & $\begin{array}{c}\text { Min }(\mathrm{S} 2) \\
\text { savings } \\
{[\mathrm{kg}]}\end{array}$ & $\begin{array}{c}\text { Max (S6) } \\
\text { savings } \\
{[\mathrm{kg}]}\end{array}$ \\
\hline 12 & 12,468 & 39 & 13 & 7,592 & $61 \%$ & 4,358 & 5,238 \\
\hline 19 & 25,736 & 112 & 47 & 14,585 & $57 \%$ & 8,372 & 10,064 \\
\hline 11 & 26,035 & 152 & 60 & 12,848 & $49 \%$ & 7,375 & 8,865 \\
\hline 27 & 5,119 & 34 & 15 & 2,310 & $45 \%$ & 1,326 & 1,594 \\
\hline 10 & 35,863 & 157 & 29 & 15,216 & $42 \%$ & 13,101 & 15,749 \\
\hline 5 & 14,018 & 43 & 18 & 4,821 & $34 \%$ & 8,302 & 9,979 \\
\hline 22 & 8,261 & 47 & 14 & 2,076 & $25 \%$ & 1,192 & 1,433 \\
\hline 3 & 29,278 & 94 & 24 & 7,299 & $25 \%$ & 10,474 & 12,591 \\
\hline 15 & 11,953 & 68 & 11 & 1,676 & $14 \%$ & 1,443 & 1,735 \\
\hline 24 & 90,071 & 351 & 104 & 12,186 & $14 \%$ & 3,498 & 4,204 \\
\hline 20 & 12,761 & 46 & 8 & 1,188 & $9 \%$ & 1,022 & 1,229 \\
\hline 23 & 37,439 & 132 & 17 & 3,045 & $8 \%$ & 2,622 & 3,152 \\
\hline 13 & 61,486 & 240 & 27 & 3,197 & $5 \%$ & 2,752 & 3,308 \\
\hline 16 & 35,114 & 135 & 8 & 1,710 & $5 \%$ & 981 & 1,180 \\
\hline 14 & 33,597 & 82 & 2 & 1,233 & $4 \%$ & 708 & 851 \\
\hline 9 & 84,646 & 99 & 12 & 1,947 & $2 \%$ & 1,676 & 2,015 \\
\hline 4 & 23,211 & 108 & 3 & 438 & $2 \%$ & 377 & 453 \\
\hline 17 & 13,744 & 87 & 5 & 204 & $1 \%$ & 176 & 211 \\
\hline 21 & 67,704 & 231 & 13 & 973 & $1 \%$ & 838 & 1,007 \\
\hline 8 & 64,239 & 165 & 5 & 761 & $1 \%$ & 656 & 788 \\
\hline 7 & 104,533 & 116 & 3 & 699 & $1 \%$ & 2,006 & 2,411 \\
\hline 26 & 143,256 & 355 & 3 & 297 & $0 \%$ & 341 & 410 \\
\hline SUM & 940,532 & 2,893 & 441 & 96,301 & $10 \%$ & 73,594 & 88,467 \\
\hline
\end{tabular}

For the 27 case studies analysed, savings due to steel floor beams optimisation could have brought up to $35 \%$ steel mass savings for the frame. The greatest savings were noticed in case studies 5 and 19 where universal beams for composite floors were used. On the top of that, case study 7 was characterised by the highest steel use for $\mathrm{m}^{2}$ of the building, and $2 / 3$ all beams were calculated as non-composite.

\subsection{Whole-life embodied carbon savings for case studies}

To assess carbon content, the framework included in BS EN 15643-1:2010 "Sustainability of construction works. Sustainability assessment of buildings. General framework" [51] and developed by the Technical 
Steel mass savings due to steel members optimisation (steel frame only)

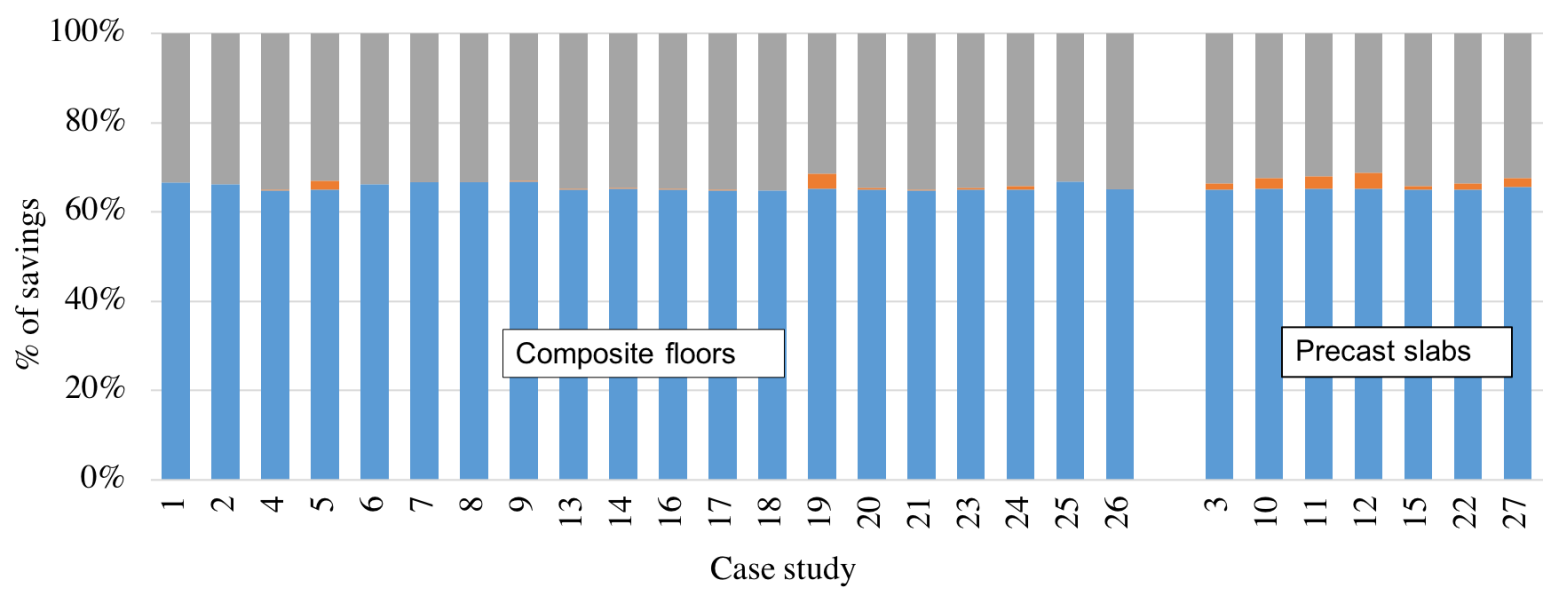

- EC - the "Lightest Beam Method" (S2) for non-composite UB and "Maximum UR" method for the rest of steel members

- Max - additional savings for analysed non-composite UB (S6)

- Possible steel mass in structure

Figure 8: Mass savings due to member optimisation for 27 case studies.

Overall steel mass savings for each building due to steel members optimisation (steel frame only)

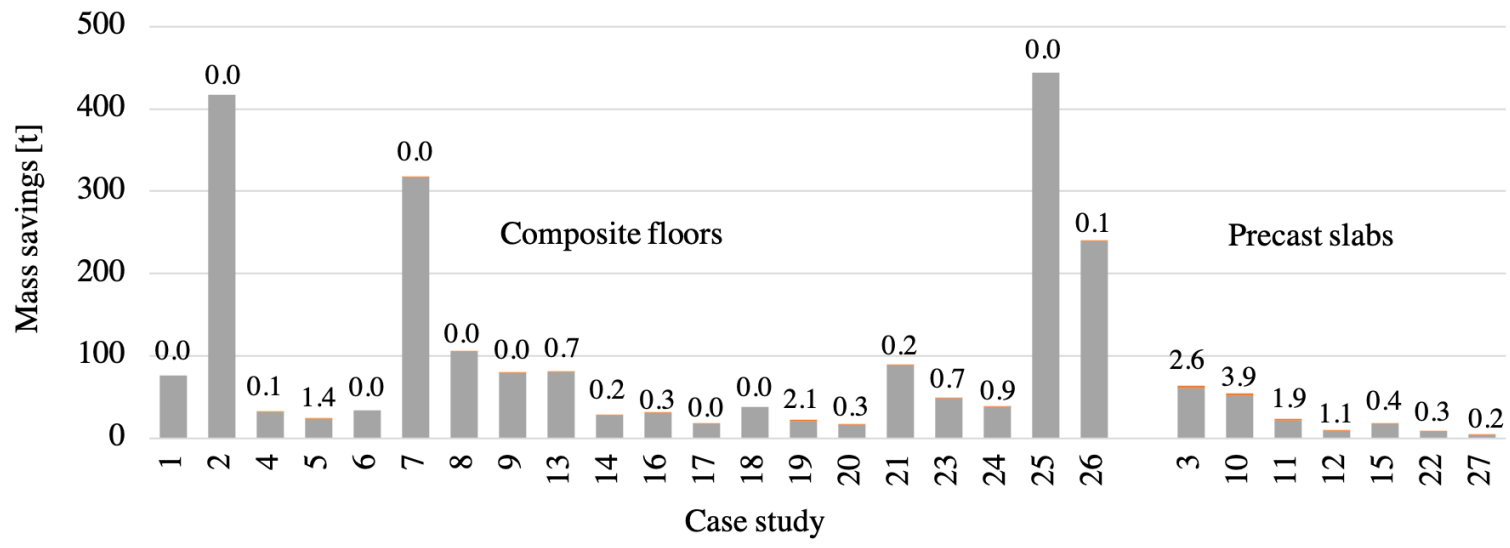

— Max - additional savings for analysed non-composite UB (S6)

घEC - the "Lightest Beam Method" (S2) for non-composite UB and "Maximum UR" method for the rest of steel members

Figure 9: Overall steel mass savings for each building due to steel members optimisation (additional savings in tonnes (Max) are presented over the graph bars).

412

413

Committee 350 (CEN/TC350) "Sustainability of construction works" [52] was used. The framework specifies standards for the sustainability assessment of buildings - EN 15978:2011 [53], as well as for products used in construction - EN 15804:2014 [54]. Both represent the modular approach, within the system boundary presented 
on Figure 10. Table 10 presents carbon impact of materials used in this study. They include modules A (Initial embodied impacts), C (End-of-Life impacts - EoF) and D (Reuse, recovery or recycling potential) [53]). In all calculations, Module D was considered separately. Embodied carbon in-use (Modules B1-B5) was excluded due to lack of the data $[17,18,19]$. Calculations also exclude operation impact (Modules B6 and B7). Whole-life carbon was estimated under the assumption that for an office building located in London, for an assumed 60-year lifespan, initial embodied carbon represents $1 / 3$ of whole-life building emissions $[9,17]$. The structural frames however represent $20-30 \%$ of whole-life carbon [21, 22, 23].

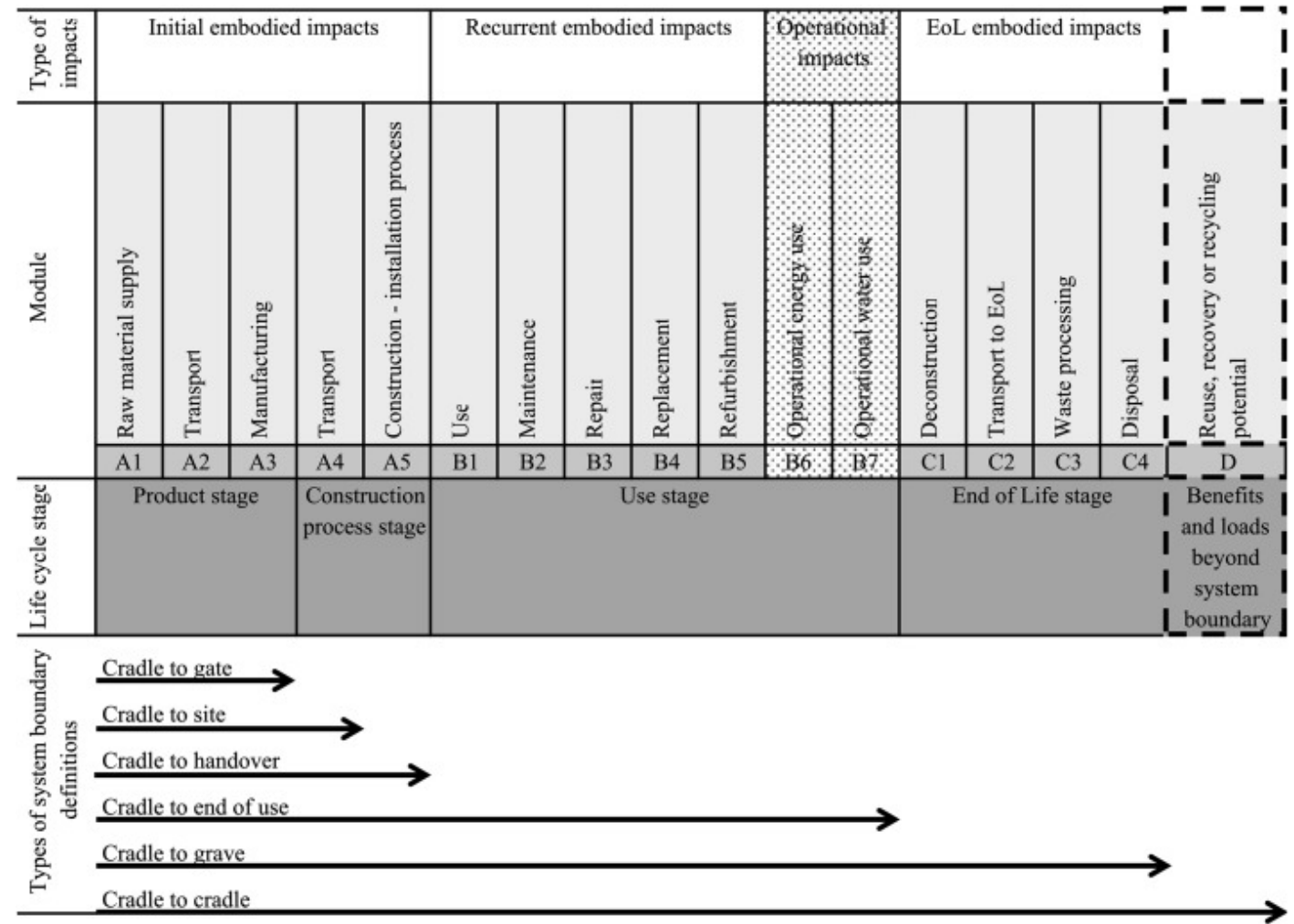

Figure 10: System boundaries definitions in relation to the life cycle stages of a building [18].

A carbon assessment for the original design is presented in Figure 11 with a structural material breakdown in Figure 12. The savings due to steel floor beams optimisation varies between $17 \%$ and $35 \%$ of initial embodied carbon for the frame (Figure 13). The highest initial carbon was found for buildings with composite floors that used UB beams calculated as non-composite beams.

The steel structure is responsible for half of initial embodied carbon (15\% of whole-life carbon) [9, 17]. Mass savings of $35 \%$ in the steel structure result in up to $5 \%$ of whole-life carbon savings for an assumed 60 -year lifespan (with the same superimposed loan assumptions). This does not include savings due to the use of less 
Table 10: Initial, End-of-Life impact and Reuse, recovery or recycling potential for structural materials. Detailed calculations are available at https://doi.org/10.17863/CAM.47336. RC - reinforced concrete (with reinforcement ratio 1\%), PS - precast slab (Hollowcore), UB Universal Beams, FB - Fabricated Beams, SD - Steel Decking.

\begin{tabular}{|c|c|c|c|c|c|c|c|}
\hline Module & $\begin{array}{c}\mathbf{R C} 32 / 40 \\
\mathrm{kgCO}_{2} e q / \mathrm{kg}\end{array}$ & $\begin{array}{c}\text { Concrete } \mathbf{C 3 2} / \mathbf{4 0} \\
\mathrm{kgCO}_{2} e q / \mathrm{kg}\end{array}$ & $\begin{array}{c}\text { Rebar } \\
\mathrm{kgCO}_{2} e q / \mathrm{kg}\end{array}$ & $\begin{array}{c}\text { PS } \\
\mathrm{kgCO}_{2} e q / \mathrm{kg}\end{array}$ & $\begin{array}{c}\text { UB } \\
\mathrm{kgCO}_{2} e q / \mathrm{kg}\end{array}$ & $\begin{array}{c}\text { FB } \\
\mathrm{kgCO}_{2} e q / \mathrm{kg}\end{array}$ & $\begin{array}{c}\text { SD } \\
\mathrm{kgCO}_{2} e q / \mathrm{kg}\end{array}$ \\
\hline A1 & 0.175 & 0.129 & 1.381 & 0.147 & 1.304 & 1.977 & 2.517 \\
\hline A2 & 0.007 & 0.006 & 0.047 & 0.010 & 0.063 & 0.052 & 0.061 \\
\hline A3 & 0.003 & 0.003 & 0.021 & 0.027 & 0.183 & 0.432 & 0.153 \\
\hline A4 & 0.003 & 0.003 & 0.018 & 0.032 & 0.027 & 0.027 & 0.027 \\
\hline A5 & 0.004 & 0.001 & 0.107 & 0.005 & 0.018 & 0.018 & 0.018 \\
\hline B & - & - & - & - & - & - & - \\
\hline $\mathrm{C} 1$ & 0.004 & 0.004 & 0.002 & 0.005 & 0.005 & 0.099 & 0.005 \\
\hline $\mathrm{C} 2$ & 0.004 & 0.003 & 0.039 & 0.003 & 0.015 & 0.015 & 0.003 \\
\hline $\mathrm{C} 3$ & 0.003 & 0.003 & 0.004 & -0.012 & 0.002 & 0.002 & 0.002 \\
\hline $\mathrm{C} 4$ & 0.000 & 0.000 & 0.001 & 0.002 & 0.003 & 0.003 & 0.002 \\
\hline D & 0.015 & 0.006 & 0.258 & 0.015 & 0.802 & 0.802 & 1.313 \\
\hline $\begin{array}{c}\text { Sum } \\
\text { excl. D }\end{array}$ & 0.195 & 0.141 & 1.622 & 0.212 & 1.620 & 2.624 & 2.787 \\
\hline $\begin{array}{l}\text { Sum } \\
\text { incl. D }\end{array}$ & 0.180 & 0.135 & 1.364 & 0.198 & 0.818 & 1.822 & 1.474 \\
\hline
\end{tabular}

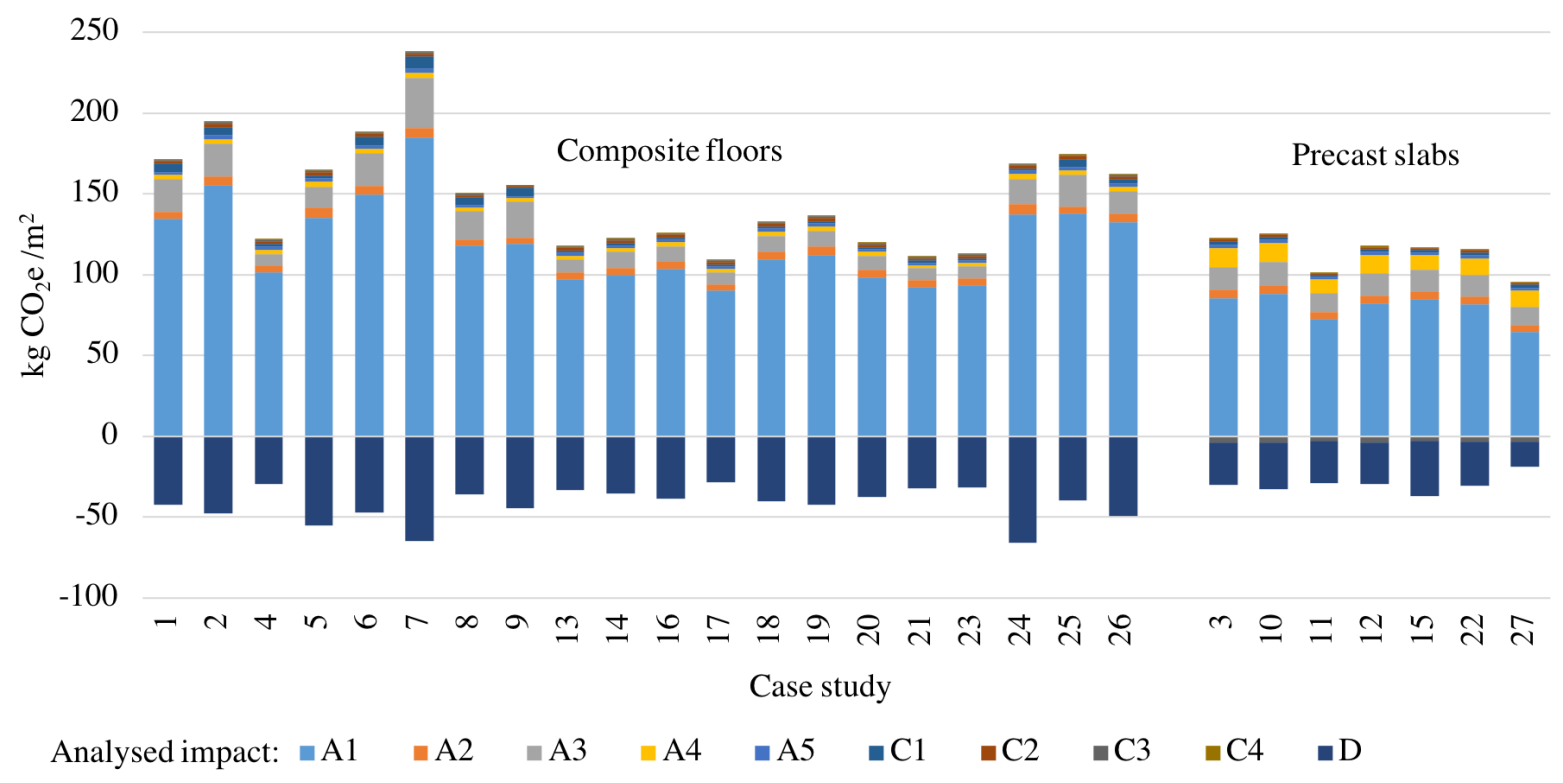

Figure 11: Initial, End-of-Life impact and Reuse, recovery or recycling potential for structural frame, including floors.

conservative assumptions (e.g. floor live load reduction, dead load reduction), using layout optimisation, or using less carbon intensive materials. Moving towards net-zero operational carbon buildings, we can expect that initial and in-use embodied carbon will represent a 50\% share of total emissions. In this case, we might achieve closer to $10 \%$ of whole-life carbon savings for a 60 -year building lifespan. 


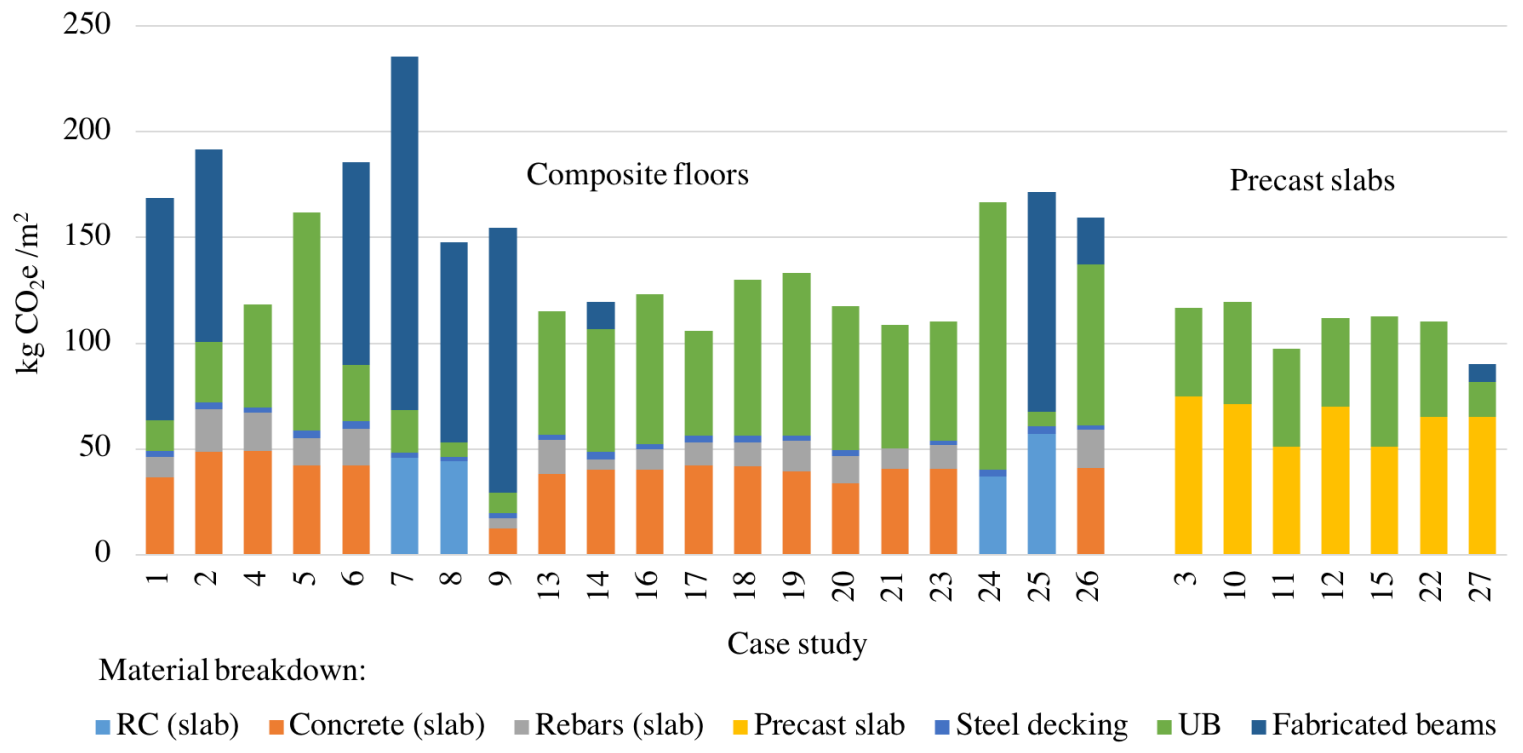

Figure 12: Initial and End-of-Life impact for structural frame, including floors - material breakdown.

Initial embodied carbon savings due to steel members optimisation (frame, slabs and columns)

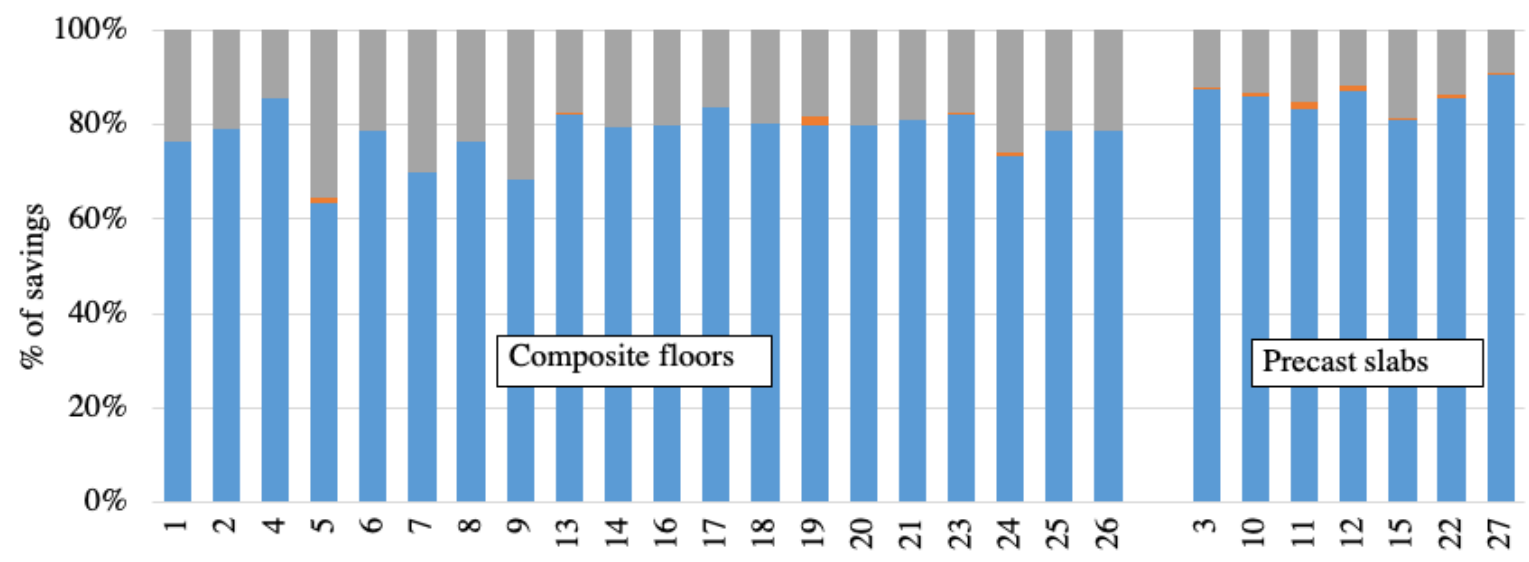

Case study

=EC - the "Lightest Beam Method" (S2) for non-composite UB and "Maximum UR" method for the rest of steel members

$\varpi$ Max - additional savings for analysed non-composite UB (S6)

n Possible embodied carbon in structure

Figure 13: Initial embodied carbon savings for analysed case studies (frame, slabs). 


\section{Conclusions}

The analysis in this paper has only considered savings due to cross-section optimisation, as it is the most accessible form of optimisation for structural engineers without changing the floor system or beam layout. It was found that $26.5 \%$ mass savings could be achieved for non-composite beams by choosing the lightest beams in accordance with the Eurocodes. Relaxing serviceability limits and altering inputs leads to an additional $8 \%$, giving $34.5 \%$ less steel. Although design to ensure full code compliance brings significant steel and embodied carbon savings, the loosening of serviceability criteria increases savings by $30 \%$ and therefore is strongly advised as represents "low-hanging fruit" of reducing embodied carbon in buildings. Overall, this reduces initial carbon by up to $35 \%$ in the frame which represents up to $5 \%$ of whole-life carbon for a 60 -year building lifespan. For a net-zero operational carbon building, this can reach even $10 \%$ of whole-life carbon.

It was found that by relaxing one constraint, another starts to govern and therefore the mass savings can be limited. Small changes in input limitations can affect only some criteria and thus the relative importance of SLS limits can change. A change in input constant has been shown to affect the extent to which serviceability governs and consequently the significance of the chosen serviceability limits. Considering the change in steel yield strength, while the design constraints remained unchanged, the proportion of beams governed by SLS shifts from $47.5 \%$ to $76.7 \%$. Using alternative design constraints - calculation of deflection using variable loads, and using vibration limits as $3 \mathrm{~Hz}$, the proportion of beams governed by SLS drops significantly to $12.4 \%$.

During this study, it was found that determining potential mass savings based on the"Maximum UR" methodology is an oversimplification and the results overestimate the savings.

In addition to rationalisation and repetition, the main reason for low material utilisation is the use of 0.8 UR by the structural designer as a target instead of 1.0 UR. This paper shows that in order to achieve mass and carbon saving, all structural design software (e.g. Fastrak) should adopt the light weight approach, e.g. the Lightest Beam Method and, above all, not allow the designer to target low utilisation.

This work does not include any other savings that could be achieved due to layout optimisation, live load reduction, use of low embodied carbon materials or a material reuse strategy; they are the subject of future research of the authors.

\section{Acknowledgements}

We would like to warmly thank Price \& Myers for their invaluable help in this analysis and their expertise. This paper is part of the project "Minimising Energy in Construction (MEICON)" funded by the Engineering and Physical Sciences Research Council (EPSRC) under grant EP/P033679/2. 
9. Data access statement

All data used in this paper are available online at https://doi.org/10.17863/CAM. 47336 


\section{Bibliography}

[1] Reinventing construction: A route to higher productivity. McKinsey \& Company (2017).

[2] Global Status Report 2018 - Towards a zero-emission, efficient, and resilient buildings and construction sector, Global Alliance for Building and Construction and International Energy Agency (2018).

[3] Perspectives for the Clean Energy Transition - The critical role of buildings. IEA, Paris, 2019, www . iea. org/publications/reports/PerspectivesfortheCleanEnergyTransition/.

[4] World Population Review 2019. worldpopulationreview.com/, 2019-07-02.

[5] Report of the Conference of the Parties on its twenty-first session, held in Paris from 30 November to 13 December 2015, Part two: Action taken by the Conference of the Parties at its twenty-first session. Tech. Rep., United Nations, Framework Convention on Climate Change (29 January 2016).

[6] Allwood, J., Ashby, M., Gutowski, T. \& Worrell, E. Material efficiency: A white paper. Resources, Conservation and Recycling 55, 362-381 (2011).

[7] Allwood, J. et al. Sustainable materials: with both eyes open (Citeseer, 2012).

[8] Global warming of $1.5^{\circ} \mathrm{C}$ - Summary for Policymakers. Intergovernmental Panel on Climate Change (IPPC) (2018). URL https://www.ipcc.ch/site/assets/uploads/sites/2/2018/07/SR15_SPM_ version_stand_alone_LR.pdf.

[9] RICS professional standards and guidance: Whole life carbon assessment for the built environment, RICS (2017).

[10] Geoffrey, P. \& Jones, C. Embodied energy and carbon in construction materials Energy 161, 87-98 (2008).

[11] Moynihan, M. \& Allwood, J. Utilization of structural steel in buildings. Proc. R. Soc. A 470, 20140170 (2014).

[12] Malmqvist, T. et al. Design and construction strategies for reducing embodied impacts from buildings case study analysis. Energy and Buildings 166, 35 - 47 (2018). URL http://www. sciencedirect .com/ science/article/pii/S0378778817321576.

[13] Sartori, I. \& Hestnes, A. Energy use in the life cycle of conventional and low-energy buildings: A review article. Energy and Buildings 39, 249 - 257 (2007). URL http://www. sciencedirect.com/science/ article/pii/S0378778806001873. 
[14] Giordano, R., Serra, V., Tortalla, E., Valentini, V. \& Aghemo, C. Embodied energy and operational energy assessment in the framework of nearly zero energy building and building energy rating. Energy Procedia 78, 3204 - 3209 (2015). URL http://www.sciencedirect.com/science/article/pii/ S1876610215025138. 6th International Building Physics Conference, IBPC 2015.

[15] De Wolf, C., Francesco, P. \& Moncaster, A. Measuring embodied carbon dioxide equivalent of buildings: A review and critique of current industry practice. Energy and Buildings 140, 68-80 (2017). URL http://www.sciencedirect.com/science/article/pii/S0378778817302815.

[16] Evaluation of Embodied Energy and CO2eq for Building Construction (Annex 57) - Subtask 2: A Literature Review. Tech. Rep., International Energy Agency, Institute for Building Environment and Energy Conservation (August 2016).

[17] Net zero carbon buildings: A framework definition. UK GBC, Advancing Net Zero (2019).

[18] Moncaster, A., Rasmussen, F., Malmqvist, T., W.A., H. \& Birgisdottir, H. Widening understanding of low embodied impact buildings: Results and recommendations from 80 multi-national quantitative and qualitative case studies. Journal of Cleaner Production 235, 378-393 (2019). URL http: //www . sciencedirect . com/science/article/pii/S0959652619321985.

[19] Pomponi, F., Moncaster, A. \& De Wolf, C. Furthering embodied carbon assessment in practice: Results of an industry-academia collaborative research project. Energy and Buildings 167, 177-186 (2018). URL http://www.sciencedirect.com/science/article/pii/S0378778817325720.

[20] EN 1990: Eurocode: Basis of structural design, howpublished = EC, year $=2002$.

[21] Nadoushani, Z., Moussavi, S. \& Akbarnezhad, A. Effects of structural system on the life cycle carbon footprint of buildings. Energy and Buildings 102, 337-346 (2015).

[22] Dimoudi, A. \& Tompa, C. Energy and environmental indicators related to construction of office buildings. Resources, Conservation and Recycling 53, 86-95 (2008).

[23] Luo, Z., Yang, L. \& Liu, J. Embodied carbon emissions of office building: a case study of China's 78 office buildings. Building and Environment 95, 365-371 (2016).

[24] Eleftheriadis, S., Dunant, C., Drewniok, M., Rogers-Tizard, W. \& Kyprianou, C. Comparative numerical analysis for cost and embodied carbon optimisation of steel building structures. Advances in Computational Design 3 (4 Special Issue), 385-404 (2018). 
[25] BS EN 1990: 2002+A1:2005 — Basis of structural design. BSI (2009).

[26] Orr, J., Drewniok, M., Copping, A., Emmitt, S. \& Ibell, T. Minimizing Energy in Construction - Survey of Structural Engineering Practice. MEICON project Report, Cambridge (2018).

[27] Dunant, C., Drewniok, M., Eleftheriadis, S., Cullen, J. \& Allwood, J. Regularity and optimisation practice in steel structural frames in real design cases. Resources, Conservation and Recycling 134, 294-302 (2018).

[28] Orr, J., Darby, A., Ibell, T., Evernden, M. \& Otlet, M. Concrete structures using fabric formwork. Structural Engineer 89, 20-26 (2011).

[29] EN 1991-1-1:2002 Eurocode 1: Actions on structures - Part 1-1: General actions - Densities, self-weight, imposed loads for buildings. EC (2002).

[30] Orr, J. et al. Minimising energy in construction: Practitioners' views on material efficiency. Resources, Conservation and Recycling 140, 125 - 136 (2018). URL http://www . sciencedirect.com/science/ article/pii/S0921344918303380.

[31] NA+A1:2014 to BS EN 1993-1-1:2005+A1:2014, UK National Annex to Eurocode 3: Design of steel structures. General rules and rules for buildings. British Standards Institution (2014).

[32] Rackham, J., Couchman, G. \& Hicks, S. Composite slabs and beams using steel decking: best practice for design and construction (2009).

[33] Eleftheriadis, S., Dunant, C., Drewniok, M. \& Rogers-Tizard, W. A computational paradigm for the optimisation of steel building structures based on cost and carbon indexes in early design stages. In Digital Proceedings of the 24th EG-ICE International Workshop on Intelligent Computing in Engineering 2017, 64-73 (2017).

[34] Dunant, C., Drewniok, M., Orr, J. \& Allwood, J. Good early stage design decisions can halve embodied CO2 and lower structural frames cost. Structures, submitted 29/01/2020 .

[35] Baldock, R. et al. Structural optimisation in building design practice: case-studies in topology optimisation of bracing systems. Ph.D. thesis, University of Cambridge (2007).

[36] Gibbons, C. Economic steelwork design. Struct Eng. 73(15) (1995).

[37] D'Amico, B. \& Pomponi, F. Accuracy and reliability: A computational tool to minimise steel mass and carbon emissions at early-stage structural design. Energy and Buildings 168, 236 - 250 (2018). URL http://www.sciencedirect.com/science/article/pii/S0378778817336198. 
[38] Goodchild, C., Webster, R. \& Elliott, K. Economic concrete frame elements to Eurocode 2: A pre-scheme handbook for the rapid sizing and selection of reinforced concrete frame elements in eulti-storey buildings designed to Eurocode 2 (Concrete Center, 2009). URL https://books.google.co.uk/books?id= WpjvcQAACAAJ.

[39] Campbell, J. Serviceability optimisation of steel framed buildings. Masters dissertation supervised by Dr. J. Orr, Department of Engineering, University of Cambridge, United Kingdom (2019).

[40] Blue Book - SCI P363. SCI (2018).

[41] NA to BS EN 1990: 2002+A1:2005 UK National Annex for Eurocode - Basis of structural design, howpublished $=$ BSI, month $=$ jun, year $=2009$.

[42] NA to BS EN 1991-1-1:2002 UK National Annex to Eurocode 1: Actions on structures - Part 1-1: General actions - Densities, self-weight, imposed loads for buildings, howpublished $=\mathrm{BSi}$, year $=2002$.

[43] BS EN 1993-1-1:2005,Eurocode 3: Design of steel structures. General rules and rules for buildings. British Standards Institution (2005).

[44] Smith, A., Hicks, S. \& Devine, P. Design of floors for vibration: A new approach (Steel Construction Institute Ascot, Berkshire, UK, 2007).

[45] Hicks, S., Brozzetti, J., Rémy, B. \& Lawson, R. Dimensionnement des planchers mixtes acier béton vis-à-vis des vibrations. Construction métallique 40, 3-31 (2003).

[46] P375: Fire resistance design of steel framed buildings., SCI, London (2012).

[47] BS 5950-1:2000 Structural use of steelwork in building. Code of practice for design. Rolled and welded sections. British Standards Institution (2001).

[48] P354: Design of floors for vibration, SCI, London (2009).

[49] Melcher, J., Kala, Z., Holickỳ, M., Fajkus, M. \& Rozlívka, L. Design characteristics of structural steels based on statistical analysis of metallurgical products. Journal of Constructional Steel Research 60, 795-808 (2004).

[50] Kala, Z. Influence of partial safety factors on design reliability of steel structures-probability and fuzzy probability assessments. Journal of Civil Engineering and Management 13, 291-296 (2007). 
574 [51] BS EN 15643:2010 - Sustainability of construction works. Sustainability assessment of buildings. General 575 framework (October 2010).

576 [52] CEN/TC 350 - Sustainability of construction works. http://bit. 1y/2yfMMa0, accessed on 26 July 2019.

577 [53] BS EN 15978:2011 - Sustainability of construction works. Assessment of environmental performance of $578 \quad$ buildings. Calculation method (30 November 2011).

579 [54] BS EN 15804:2012+A1:2013 - Sustainability of construction works. Environmental product declarations. Core rules for the product category of construction products (30 November 2011). 